\title{
Quantifying impacts of plastic debris on marine wildlife identifies ecological breakpoints
}

\author{
Nina Marn ${ }^{\mathrm{a}, \mathrm{b}, 1,2}$, Marko Jusup ${ }^{\mathrm{c}, 1}$, S.A.L.M. Kooijman ${ }^{\mathrm{d}}$, and Tin Klanjscek ${ }^{\mathrm{a}, 2}$ \\ ${ }^{a}$ Division for Marine and Environmental Research, Rudjer Boskovic Institute, HR-10002 Zagreb, Croatia; ${ }^{b}$ School of Biological Sciences, The University of Western Australia, \\ Crawley WA 6009, Australia; ${ }^{\mathrm{c}}$ Tokyo Tech World Research Hub Initiative (WRHI), Institute of Innovative Research, Tokyo Institute of Technology, Tokyo 152-8552, Japan; ${ }^{\text {Vrije }}$ \\ Universiteit Amsterdam, Amsterdam 1081, The Netherlands
}

This manuscript was compiled on August 1, 2020

\begin{abstract}
Quantifying sub-lethal effects of plastics ingestion on marine wildlife is difficult, but key to understanding the ontogeny and population dynamics of affected species. We developed a method that overcomes the difficulties by modelling individual ontogeny under reduced energy intake and expenditure caused by debris ingestion. The predicted ontogeny is combined with a population dynamics model to identify ecological breakpoints: cessation of reproduction or negative population growth. Exemplifying this approach on loggerhead turtles, we find that between $3 \%$ and $25 \%$ of plastics in digestive contents causes a $2.5 \%$ to $20 \%$ reduction in perceived food abundance and total available energy, resulting in a $10 \%$ to $15 \%$ lower condition index and $10 \%$ to $88 \%$ lower total seasonal reproductive output compared to unaffected turtles. The reported plastics ingestion is insufficient to impede sexual maturation, but population declines are possible. The method is readily applicable to other species impacted by debris ingestion.
\end{abstract}

Physiological energetics | Conservation | Sea turtles | Stressors | Debris ingestion

$\mathbf{P}$ lastic debris in marine environments represents a global anthropogenic pressure that, despite heightened awareness and preventive regulations (Thompson et al., 2009), is likely to keep increasing for the foreseeable future (Moore, 2008; Jambeck et al., 2015). Annually, between 4-12 million tons of plastic waste from land (Jambeck et al., 2015) and 1-2 million tons from rivers (Lebreton et al., 2017) find their way into the sea, making plastic items and microplastic particles omnipresent in global oceans (Derraik, 2002; Moore, 2008; Barnes et al., 2009; Cozar et al., 2014; Eriksen et al., 2014).

Negative effects of plastic debris on over 700 marine species have already been documented, and sea turtles are among the top three wildlife groups impacted by plastics (Gall and Thompson, 2015). Namely, all seven species of sea turtles in all major oceans have been found to ingest plastic debris (Schuyler et al., 2014a; Nelms et al., 2016; Lynch, 2018), with as many as $52 \%$ of all sea turtle individuals ingesting plastics sometime during their lifetime (Schuyler et al., 2016). Plastic debris has therefore been identified as one of the global research and conservation challenges for sea turtles (Hamann et al., 2010; Wallace et al., 2011).

Plastics ingestion occurs when sea turtles encounter and ingest debris accidentally (i.e., opportunistically) or mistake debris for prey and ingest it actively (Schuyler et al., 2012; Narazaki et al., 2013; Schuyler et al., 2014b). Data suggest that oceanic turtles are less selective and more likely to encounter floating debris while feeding on pelagic organisms (Schuyler et al., 2012), which makes them vulnerable to opportunistic plastics ingestion (Schuyler et al., 2014a; Nelms et al., 2016; Schuyler et al., 2016). This is in contrast to neritic sea turtles who are more selective and encounter fewer floating items while feeding on benthic organisms, which in turn results in predominantly active plastics ingestion (Schuyler et al., 2012). During feeding, turtles may also indirectly ingest plastics already consumed by their prey (Thompson et al., 2004; Barnes et al., 2009; Rochman et al., 2015). Indirect ingestion, in addition to environmental debris prevalence and turtle feeding ecology, partly depends on prey behaviour. Furthermore, indirectly ingested plastics are likely to be fragmented into small, hard-to-detect pieces termed microplastics that exert both physical and biochemical effects on individuals (Rezania et al., 2018). Biochemical effects intensify, whereas physical subside, inversely to particle size (Batel et al., 2016), implying that larger macroscopic debris causes mostly physical effects.

The physical effects of plastics ingestion cause a range of lethal and sub-lethal consequences. Ingested debris blocks, damages, or reduces the volume of a turtle's digestive system (Gramentz, 1988; Stahelin et al., 2012; Schuyler et al., 2014a), thus decreasing the caloric intake at best, and fatally harming the turtle at worst (Mascarenhas et al., 2004; Lazar and Gračan, 2011; Casale et al., 2016). Sub-lethal consequences of plastics ingestion, observed in other species (Connors and Smith, 1982; Ryan, 1988; Yamashita et al., 2011) and sea turtles alike (McCauley and Bjorndal, 1999; Mascarenhas et al., 2004; Stahelin et al., 2012), include slower weight gain, decreased fat deposits, less feeding activity, longer gut residence times of ingested material, and inflammation. Ingested plastics therefore has the potential to substantially reduce the physiological condition of individuals, thereby lowering their chances of survival or reproduction and, in turn, lowering the population growth rate. Our goal here is to lay the methodological foundation for quantifying these effects.

Quantifying sub-lethal effects of plastics ingestion is challenging. Studies of controlled plastics ingestion involving sea turtles are rare and limited to short periods of time (Lutz, 1990; Narazaki et al., 2013; Fukuoka et al., 2016) or a single life stage (McCauley and Bjorndal, 1999). The most elaborate efforts to date have produced a quantitative link between the number of ingested items and mortality (Santos et al., 2015; Wilcox et al., 2018), whereas sub-lethal effects have only been mentioned as "an area of considerable uncertainty and concern" for sea turtles (Gall and Thompson, 2015). Studies on quantitative, let alone mechanistic, links between plastics

NM designed the research with guidance from MJ and TK, and feedback from SALMK. NM performed individual-level and MJ population-level simulations. NM and MJ performed analyses. NM drafted the manuscript, subsequently modified by $\mathrm{NM}$ and $\mathrm{MJ}$, and revised by all authors.

Authors declare no conflict of interest.

${ }^{1} \mathrm{NM}$ and $\mathrm{MJ}$ contributed equally to this work.

${ }^{2}$ To whom correspondence should be addressed. E-mail: nmarn@irb.hr, tin@irb.hr 


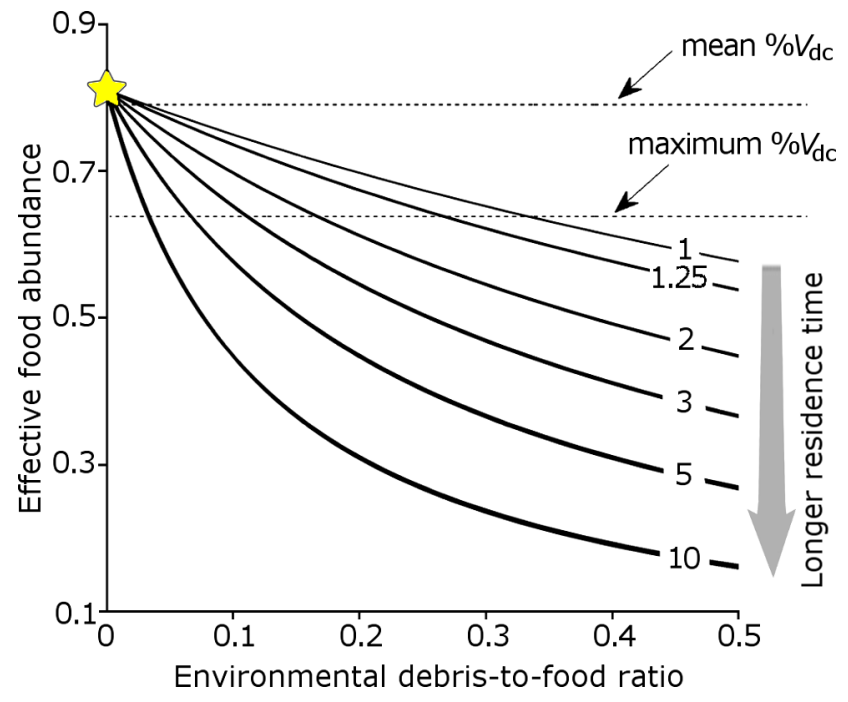

Fig. 1. Presence of plastic debris reduces effective food abundance experienced by sea turtles. As the prevalence of plastics in the environment increases relative to food, animals are more likely to ingest plastics. A direct consequence is that sea turtles experience less food abundance (top black curve) than they would in a pristine ocean (yellow star). The effect is compounded if, in addition, plastic debris has a longer residence time than food (black curves indexed by relative residence times from $1.25 \times$ to $10 \times$ ). The horizontal dashed lines mark $3 \%$ and $25 \%$ of debris in digestive contents, which corresponds to mean and maximum reported values for percentage of debris in stomach contents (Frick et al., 2009). ingestion and sub-lethal physiological or life-history effects on sea turtles are thus hard to come by. Nevertheless, there is still a lot of information on sea turtles that could be assimilated by mechanistic modelling approaches. Loggerhead turtles (Caretta caretta) are of prime interest because of the extensive information on this species from field studies, strong concerns about the damaging effects of plastics ingestion (Schuyler et al., 2014a; Nelms et al., 2016; Schuyler et al., 2016; Lynch, 2018 ), and the status as a potential bio-indicator for monitoring plastics ingestion in the Mediterranean (Fossi et al., 2018). Serious effects of plastics ingestion have been documented for post-hatchlings (McCauley and Bjorndal, 1999; Ryan et al., 2016), oceanic-stage juveniles (Pham et al., 2017), and juveniles and adults (Lazar and Gračan, 2011; Campani et al., 2013; Schuyler et al., 2014a), with some authors quoting loggerhead turtles as being "specially prone to debris ingestion" (Tomás et al., 2002). Recent reports put the incidence of plastics ingestion at an average of $49 \%$, based on 42 studies that examined three or more animals (Lynch, 2018). The ontogeny of loggerhead turtles has been characterized from the perspective of physiological energetics and successfully linked to environmental forcings such as food and temperature, to capture the observed variability among individuals within and between populations (Marn et al., 2017b,a, 2019). Here, we further extend the already validated mechanistic model of the ontogeny by accounting for plastics ingestion.

We mechanistically describe how plastics ingestion affects the ontogeny of loggerhead turtles, seeking answers to two primary questions. First, is the reported plastics ingestion sufficient to impede sexual maturation or egg production of these turtles? Second, even if individual turtles successfully mature and reproduce, can the population as a whole maintain positive growth? In doing so, we identify two ecologically critical events of interest: one is the cessation of reproduction, which we define as an individual-level breakpoint; the other is non-positive population growth which we define as a population-level breakpoint. We investigate the extent of plastics ingestion required to reach either breakpoint, and how this relates to plastic loads currently experienced by sea turtles in the wild. Further methodological details are available in the Methods section and Supplementary Information (SI) Appendix.

\section{Results}

Ingesting plastic debris has the effect of reducing effective food abundance experienced by sea turtles (Fig. 1). We quantify food abundance as a fraction of the maximum that healthy sea turtles could ingest during the same time given unrestricted continuous access to food. The reduction in effective food abundance occurs because of competition between food and debris for the limited digestive capacity of gastrointestinal tract, where the amount of debris compared to food in digestive contents at any given time is determined by two quantities. First, a debris-to-food ratio estimates how likely it is for a turtle to ingest debris instead of food; more debris in the environment results in proportionately more ingested debris (Schuyler et al., 2016). Second, the relative debris residence time estimates how much longer than food ingested debris remains inside gastrointestinal tract (Lutz, 1990; Mascarenhas et al., 2004; Valente et al., 2008). (See also SI Appendix, Fig. S1). As a baseline, our previous analysis has shown that free-ranging loggerhead turtles experience, on average, food abundance of 0.81 (Marn et al., 2017b,a). The effect of said competition between food and debris for the limited digestive capacity is nearly negligible when there is $3 \%$ of debris in digestive contents, but when there is $25 \%$ of debris in digestive contents, effective food abundance is as low as 0.64. As will be shown shortly, a drop in food abundance from 0.81 to 0.64 is already enough to considerably affect the life history of sea turtles.

Ingested debris reduces the energetic scope for growth, mat-

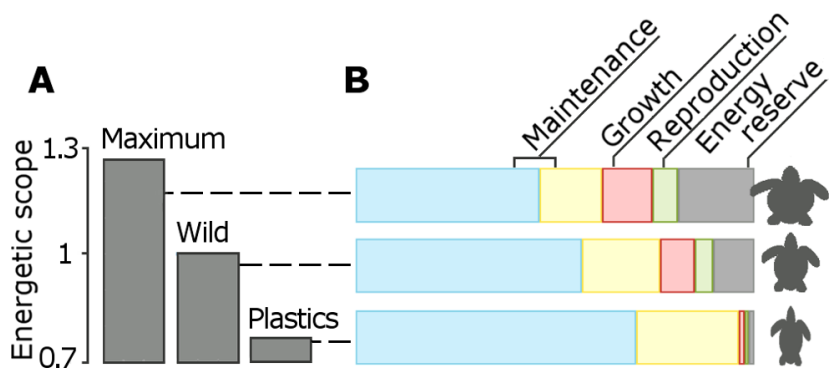

Fig. 2. Ingested debris reduces the energetic scope for growth, reproduction, and reserve accumulation of sea turtles. The decrease happens both in absolute and relative terms. Shown is the total energy budget size and the energy usage of loggerhead turtles at the moment of sexual maturation. A, The decrease in effective food abundance from 0.81 for unexposed loggerheads (Marn et al., 2017b) to 0.64 for loggerheads exposed to $25 \%$ plastics is digestive contents would mean a $24 \%$ reduction in the total energy budget size. Also plotted for reference is the energy budget size at the maximum theoretical food abundance of 1.00. B, Beside reducing the total energy budget size, lower effective food abundance leaves a smaller fraction of the energy budget available for growth, reproduction, and energy accumulation. This is because maintenance demands are largely size-driven, and loggerhead turtles mature at approximately the same size (albeit possibly at very different age) as long as food abundance is sufficient for reaching sexual maturation. 
A

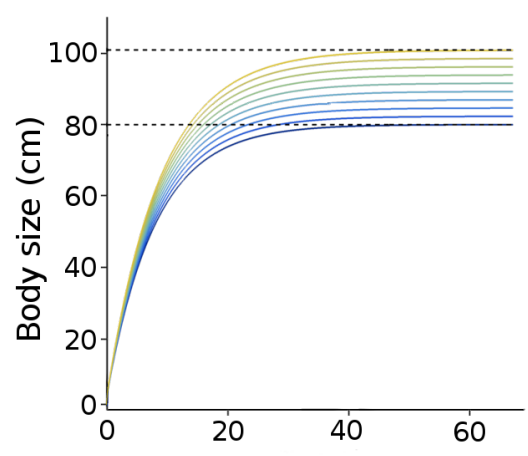

B

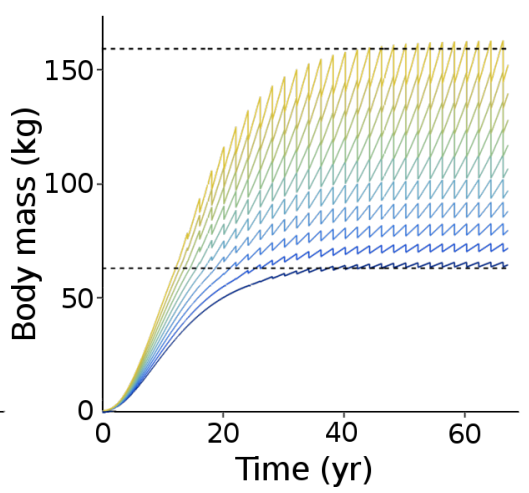

C

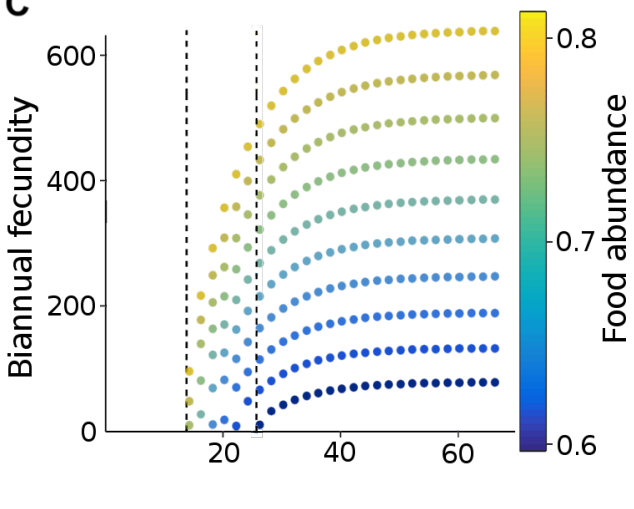

Fig. 3. Ontogenetic development of loggerhead turtles is negatively affected by higher ingestion and longer residence of plastic debris. Ingested debris competes with food for a limited digestive capacity as shown in Fig. 1, thus lowering the effective food abundance below $\approx 80 \%$ of the maximum that loggerhead turtles normally experience in the wild. This negatively affects ontogeny. A, Body size can decrease from $\approx 100 \mathrm{~cm}$ straight carapace length under normal conditions to $\approx 80 \mathrm{~cm}$, when also sexual maturation becomes delayed. B, The corresponding reduction in body mass is even more striking, falling from as much as $160 \mathrm{~kg}$ to as little as $60 \mathrm{~kg}$. Periodic mass fluctuations are due to allocation to reproduction in adults, culminating in nesting that takes place roughly biannually in loggerhead turtles. $\mathbf{C}$, The reduction in, typically biannual, fecundity is the most striking of all as the number of eggs declines from several hundreds to less than a hundred in a nesting season. Despite the large magnitude of the described negative effects, the effects may be difficult to recognize in the field due to imprecise age determination and natural variation between individuals.

uration or reproduction, and reserve accumulation (Fig. 2). For example, a turtle with an average plastics load of $3 \%$ in digestive contents, which is close to the mean reported values for loggerhead turtles (Frick et al., 2009; Clukey et al., 2017), experiences $\approx 2.5 \%$ reduction in perceived food abundance and total available energy, causing $\approx 10 \%$ lower condition index and total seasonal reproductive output. With plastics loads in excess of $25 \%$, which is the reported maximum (Frick et al., 2009 ), a fully grown turtle experiences $\approx 20 \%$ reduction in available energy, causing $\approx 15 \%$ lower condition index and $\approx 88 \%$ lower total seasonal reproductive output compared to unaffected turtles. This reduction is due to a smaller energy budget in absolute terms (Fig. 2A), but also a larger contribution of maintenance to the budget in relative terms (Fig. 2B). At the moment of sexual maturation, for example, the decrease in effective food abundance from 0.81 for unexposed individuals to 0.64 for individuals exposed to $25 \%$ plastics in digestive contents corresponds to a $24 \%$ reduction in the total energy budget size. Meanwhile, in unexposed turtles, maintenance costs comprise $78 \%$ of the energy budget, whereas in exposed ones, as much as $96 \%$ of the energy budget. With only $4 \%$ of the daily energy budget left for growth, reproduction, and reserve accumulation, exposed turtles potentially experience difficulties allocating energy to egg production simply because less energy is available for reproduction once maintenance demands are satisfied.

A particular energy budget gives rise to a particular ontogeny. For simplicity, the presented simulations describe North Atlantic loggerhead turtles experiencing a typical constant environment from hatching onward (Marn et al., 2017b); the percentage of plastics in digestive contents is the only differing factor between simulations. The ultimate body sizes of adults, expressed in terms of straight carapace length, range between $80 \mathrm{~cm}$ and $100 \mathrm{~cm}$ (Fig. 3A). The corresponding range of body masses is more dramatic, extending from as little as $60 \mathrm{~kg}$ for turtles exposed to plastics to as much as $160 \mathrm{~kg}$ for unexposed turtles (Fig. 3B). Consistent with observations under favourable conditions in the wild (Zug et al., 1986; Tiwari and Bjorndal, 2000; Tucker, 2010; Hawkes et al., 2005), unexposed turtles under simulated conditions mature already at the age of 14, and are at maximum size capable of producing up to 640 eggs in one nesting season (Fig. 3C). The sexual maturation age of exposed turtles may be substantially prolonged, followed by reduced egg production. For example, turtles that start to mature at the age of 26 years produce at maximum size only 75 eggs over a nesting season. When plastics occupies $>30 \%$ of digestive contents, effective food abundance drops below 0.61 , and turtles never mature or reproduce.

Sexual maturation and reproduction are not a guarantee of population viability. Long-term viability of a population is secured only if reproduction makes up for mortality, thereby preventing population declines (see Methods). Our simulations show that the loggerhead turtle population growth, just like sexual-maturation age, strongly depends on effective food abundance driven by both the debris-to-food ratio and relative residence times (Fig. 4). The lowest ratios and residence times result in the fastest population growth and the youngest sexualmaturation age. As long as effective food abundance permits sea turtles to mature by the age of $\approx 22$ years, the population remains viable; longer maturation times cause the population to decline even though individuals can mature (Fig. 4). Accordingly, the population-level ecological breakpoint at which population transits from growth to decline is breached before the individual-level breakpoint at which individuals stop sexually maturing. Ecological monitoring may thus show that a population has many reproducing individuals when in fact their reproductive output is insufficient to offset various causes of mortality, and the population is headed towards extinction.

\section{Discussion}

Sub-lethal effects of marine debris, though much discussed (Ryan, 1988; McCauley and Bjorndal, 1999; Barnes et al., 2009; Mato et al., 2001; Yamashita et al., 2011), have so far been deemed "particularly difficult to quantify" (Gall and Thompson, 2015). We have overcome this difficulty by developing a mechanistic modeling framework that links levels of biological organisation to quantify the effects of plastics ingestion on ontogeny and population growth of endangered 


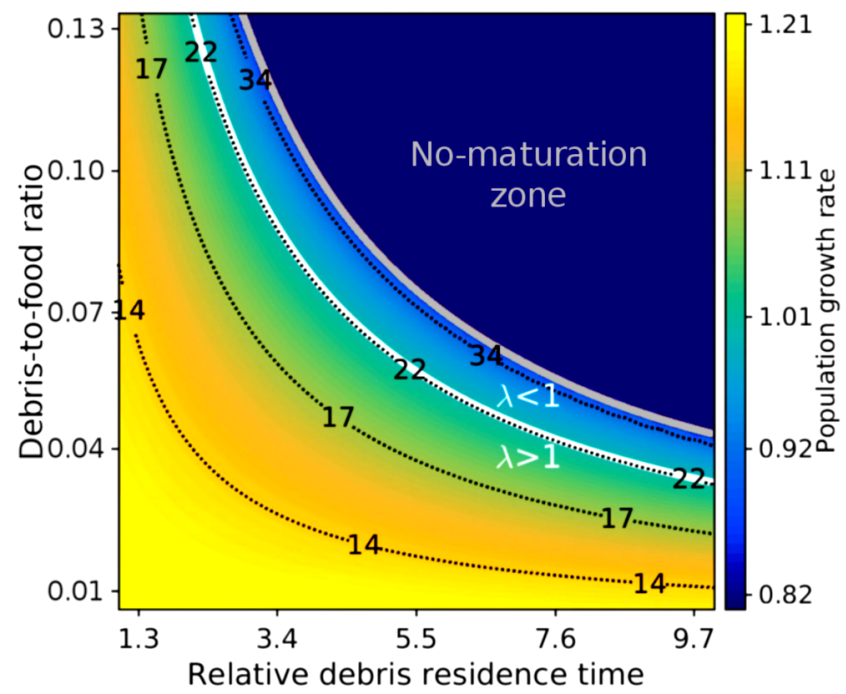

Fig. 4. Reported debris ingestion is unlikely to impede sexual maturation of sea turtles, but population declines are possible. Population growth (colormap) is overlaid with sexual maturation age (contours) as functions of (i) the environmental debris-to-food ratio ( $y$-axis) and (ii) gastrointestinal debris residence times relative to food ( $\mathrm{x}$-axis), which determine the percentage of plastics in the digestive contents and consequently the effective food abundance (see Fig. 1). White and gray isocurves respectively delineate zones of population decline (population-level breakpoint) and permanent sexual immaturity (individual-level breakpoint). The two breakpoints are separated by a $25 \%$ difference in the debris-to-food ratio or relative residence time. Plastics in turtles is known to equal $\approx 3 \%$ of digestive contents on average, but has been observed to exceed $25 \%$ (Frick et al., 2009). In the former case, loggerhead turtles in our simulations mature at the age of 14 years, which is well within the safe zone of positive population growth. In the latter case, however, turtles sexually mature only at the age of 25 years; if this became the norm, the population growth would land in the danger zone delineated by a white isocurve in the figure, and the population would be headed to extinction despite the reproducing individuals.

loggerhead turtles. The results show that amounts of plastics observed in the digestive contents of sea turtles are insufficient to prevent sexual maturation, but population declines as a consequence of plastics cannot be ruled out. Considering indefinite sexual maturation and population decline as individualand population-level ecological breakpoints, we see that while the former is far from being breached, the latter may have already been breached. A population could therefore be in distress despite a seemingly favorable physiological state of individuals.

Pinpointing indicators of physiological state that are sensitive to plastics ingestion may help identify negatively affected individuals, the prevalence of such individuals in a population, and thereby the population's state. Our framework, for example, predicts that turtles exposed to plastics have a reduced scope for growth, maturation, reproduction, and reserve accumulation. To test this prediction we looked at Fulton's condition factor (Nash et al., 2006) whose values are expected to be lower for exposed individuals due to less reserve accumulation. We used a limited dataset on loggerhead turtles from the Adriatic Sea (SI Appendix, Result 1). Exposed turtles indeed appear to have a lower condition factor than those unaffected by plastics (SI Appendix, Fig. S4), but more data is needed for a decisive conclusion. Ultimately, however, the model suggests that other indicators linked to ontogeny may be more sensitive to the long-term sub-lethal effects of plastics than the condition factor, with the added benefit of also being less sensitive to short-term fluctuations. The ontogeny of exposed turtles can be greatly delayed, causing major life-history milestones to be reached at a later age. Accordingly, if measurements of body size and fecundity were supplemented with the age of sea turtles, every individual could be positioned in one or more plots in Fig. 3, and compared against expectations calculated for that population, taking into account the average food abundance and temperature experienced by the turtles. Individuals whose position was closer to the blue (resp., yellow) side of the spectrum of expected ontogenies would then be deemed affected (resp., unaffected) by plastics. Due to inter-individual variability present even after accounting for population-specific characteristics (Marn et al., 2017a, 2019), the results would have to be interpreted in a statistical sense, i.e., based on samples of sufficient size that are currently unavailable.

Gaps in current field data, and by extension knowledge, prompted us to limit simulations to continuous average sublethal exposure to plastics. The limitation, however, is not methodological; if high-resolution field data is leveraged with the present methodology, insights into multiple ecological scenarios become possible. To illustrate, we have considered one such scenario: the potentially damaging effects of shortterm spikes in plastics ingestion on ontogeny and reproductive output of loggerheads. In these additional simulations we mimic reality by making debris ingestion stochastic, with the mean and the maximum percentage of plastics in digestive contents corresponding to the observed values of $3 \%$ and $25 \%$, respectively (SI Appendix, Result 2). The periods of favorable feeding conditions allow sea turtles to grow almost as large as if there was no exposure to plastics (SI Appendix, Fig. S5C), yet the periods of occasional starvation decrease condition and thus reproductive output (SI Appendix, Fig. S5D, E). This is worrying because body size in terms of carapace length is the easiest to measure in practice, and thus much more often reported than body mass and fecundity, although a combination of at least two of these quantities would be a better indicator of the true state in the field.

Ecologically important difference in plastics ingestion between pelagic-feeding juveniles and benthic-feeding adults could also be explored with presented methodology and additional data. Debris ingestion is likely to change over a lifetime (Nelms et al., 2016; Schuyler et al., 2014b, 2016), thus raising questions about the realistic exposure in each life stage, and about identifying which life stage is then a bottleneck in the population growth of loggerhead turtles. Similarly, not all species of sea turtles are equally affected by environmental prevalence or ingestion of debris (Nelms et al., 2016; Schuyler et al., 2016; Lynch, 2018). Species with a highly specialized or generally nutritionally poor diet may be at a higher risk by additional energy limitations imposed by plastics ingestion than, e.g., carnivorous loggerheads. Again, answers are methodologically within our reach (Mazaris et al., 2006; Schuyler et al., 2016; Ijima et al., 2019; Stubbs et al., 2020), but remain speculative until high-fidelity field data become available.

Plastics can have ecological consequences extending beyond energy limitation caused by reduction in digestive capacity of individuals. These are most likely to arise from ingested microplastics (Rezania et al., 2018), and manifest as feedbacks between energy allocation and the bioconcentration of leached toxins (Klanjscek et al., 2007). Incorporating ecotoxicology 
into the ontogenetic model presented here is conceptually straightforward (Jager et al., 2006; Jager and Zimmer, 2012), but uncovering the true nature of such dynamics is not. The process is, in fact, extremely data-intensive, implying that biochemical effects on metabolism of plastics ingestion are probably going to be quantified last.

Finally, modular structure and mechanistic underpinning of the framework allow not only exploration of additional specific ecological scenarios for the sea turtle related to plastics, but also generalizations to other species and stressors. The module for individual ontogeny can directly account for thousands of species in a rapidly expanding Add-my-Pet database (Marques et al., 2018), and can be augmented to include a number of alternative or coexistent stressors (Galic et al., 2018). Therefore, in addition to elucidating consequences of exposure to plastics important for loggerhead turtle conservation, the present study answers a long-standing call by ecotoxicologists (Kramer et al., 2011) and conservationists (Cushman, 2006; Mazaris et al., 2006) for a flexible framework relating environmental pressures to both individual- and population-level indicators. Probably the most important feature of the new framework is the ability to assimilate and make best use of disparate sources of knowledge ranging from molecular-level processes, through individual-level data and time series, to environmental and population-level indicators (Nisbet et al., 2000), taking us a big step closer to understanding the general ecological consequences of plastic pollution.

\section{Materials and Methods}

Overview. Herein, we showcase a general and flexible modeling approach aiming to relate the individual-level effects of sub-lethal exposure to a stressor and the population-level effects of such exposure in order to quantify ecological breaking points. The approach is general in the sense of pertaining to any wildlife species and multiple types of stressors. Our focus was on sea turtles and plastic debris, but we could have easily worked with another endangered or otherwise-of-interest species whose energy budget is known (Marques et al., 2018). Similarly, the stressor could have been an abiotic factor such as temperature or salinity, or anthropogenic substances such as pollutants or toxicants. The approach is modular: the outputs of one module serve as the inputs for another module, while each module's internal functioning is separate from others. To describe an individual's ontogeny we thus used dynamic energy budgets (Nisbet et al., 2000; Sousa et al., 2008, 2010; Jusup et al., 2017), although other approaches based on physiological energetics would do (Nisbet et al., 2012). Similarly, population dynamics is implementable in any number of ways, e.g., via the Euler-Lotka equation (De Roos, 2008; Beekman et al., 2019), matrix population models (Klanjscek et al., 2006; Ijima et al., 2019), physiologially structured population models (De Roos and Persson, 2002; Diekmann et al., 2003), integral projection models (Smallegange et al., 2017). Finally, we modeled the effects of debris ingestion in the form of competition between food and plastics for available digestive capacity. We assumed that ingested debris occupied a fraction of digestive capacity, but delivered zero digestible energy. Below, each module is conceptually introduced; mathematical derivations and other details are in the SI Appendix, Methods.

Ontogeny. We relied on physiological energetics to generate the ontogenetic development of individuals as a function of exposure to external factors (food, temperature, stressors, etc.). Physiological energetics contrasts energy sources and sinks, and thus determines the proportion of ingested energy available for growth, maturation, and reproduction. We used the standard dynamic energy budget model because of an existing and detailed adaptation to loggerhead turtles (Marn et al., 2017b,a, 2019), and straightforward application to more than 2000 other species* (Marques et al., 2018).

The model expresses body size, $L$, as a function of age, $a$, via

$$
\frac{\mathrm{d} L}{\mathrm{~d} a}=\dot{G}(i \text {-state, } e \text {-state }),
$$

where $\dot{G}=\dot{G}$ ( $i$-state, $e$-state) is a growth function dependent on the individual's state, e.g., body size $L$ ( $i$-state variables), and the state of the environment, e.g., the aforementioned abiotic factors and anthropogenic substances (e-state variables). A concrete functional form of $G$ is decided by the animal's energy allocation scheme or simply the energy budget, the side-product of which is also a fecundity function, $F=\dot{F}$ ( $i$-state, $e$-state). The energy budget is only indirectly inferable by specifying model assumptions and testing how well the resulting model fits empirical data. The assumptions of the standard dynamic energy budget model, as well as the consequent energy budget, are detailed in the SI Appendix, Methods. The model parameters for North Atlantic loggerhead turtles produce realistic predictions with a good fit to observed data (See Marn et al. $(2017 \mathrm{~b}, \mathrm{a})$ and the online Add-my-pet collection* for more information on model calibration and comparison to observations). Ontogenies were simulated at the temperature of $21.8^{\circ} \mathrm{C}$ and a range of effective food abundance (see Fig. 1).

Population growth. Key ingredients for determining the long-term population growth rate, $\dot{r}$, are fecundity $\dot{F}$ and survival $S$ as functions of age. This is most evident by writing the Euler-Lotka equation of population growth

$$
1=\int_{0}^{\infty} e^{-\dot{r} a} \dot{F}(a) S(a) \mathrm{d} a .
$$

Generally, however, fecundity and survival depend on $i$-state and $e$-state variables, with body size $L$ often being the dominant variable that drives major ecological events (De Roos and Persson, 2002). To calculate the loggerhead population growth, we selected size as the dominant variable driving major ecological events, and obtained the survival curves by integrating size-dependent hazard rates found in the literature (Heppell et al., 2003; Sasso et al., 2006) (SI Appendix, Fig. S6). The individual-level energy budget gives access to environment-dependent fecundity function $\dot{F}=\dot{F}(L, e$-state $)=\dot{F}(L)$, and by means of Eq. (1), to age-length relationship $L=L(e$-state; $a)=L(a)$. The composition of functions $\dot{F}=\dot{F}[L(a)]$ is then directly insertable into Eq. (2) to yield a population growth rate sensitive to the specifics of ontogenetic development. Analogous reasoning applies to composition $S=S[L(a)]$ with the exception that survival is, at best, partly inferable from the individual's energy budget in the form of aging-related hazard (van Leeuwen et al., 2010) because natural (diseases and predation) or anthropogenic (direct exploitation or collateral damage) hazards almost always dominate. We reported population growth in terms of $\lambda=\exp \left(\dot{r} / \dot{r}_{0}\right)$, where we set the reference growth rate to $\dot{r}_{0}=1 \mathrm{y}^{-1}$. The population is thus growing if $\lambda>1$, declining if $\lambda<1$, and stagnating if $\lambda=1$.

Debris ingestion. We described food abundance in terms of quantity $0 \leq f<1$ representing a fraction of the maximum ingestion rate for individuals of a given size. The value of $f$ reflects food supply in the environment because $f=0$ when supply ceases, and $f \rightarrow 1$ when supply is unlimited. Assuming that individuals spend time searching for and then clearing food (Jusup et al., 2017), the relationship between $f$ and food supply $X$ becomes $f=X /\left(X+K_{X}\right)$, where $K_{X}$ is known as the half-saturation constant for food. This constant is a compound parameter containing information on how aptly food is searched for and cleared by the animal. Therefore, if plastic debris is mistaken for food, some of the searching and clearing efforts are in vain, and the half-saturation constant should increase in the presence of plastics. We modeled this by assuming that a fraction of digestive capacity is occupied by ingested debris (SI Appendix, Methods). Instead of $f$, turtles experience effective food abundance $f_{\text {eff }}$, with $K_{X}$ replaced by $K_{\text {eff }}=K_{X}\left(1+Y / K_{Y}\right)$, where $Y$ is the supply of plastics in the environment, and $K_{Y}$ is an analogue of the half-saturation constant, but now for plastic debris instead of food. Quantity $f_{\text {eff }}$ is related to food abundance $f$ via

$$
f_{\text {eff }}=\frac{f}{1+f R \frac{Y}{X}},
$$

*https://www.bio.vu.nl/thb/deb/deblab/add_my_pet 
where dimensionless $R$ is the gastrointestinal residence time of plastics relative to food, and $Y / X$ is the environmental plastics-tofood ratio. Previous work (Marn et al., 2017b) shows that loggerhead turtles in the wild experience food abundance $f=0.81$. Ranges of simulated $R$ and $Y / X$ were determined from passage time of plastics relative to food (Lutz, 1990; Mascarenhas et al., 2004; Valente et al. 2008), and environmental debris prevalence (Moore et al., 2001 Figueiredo and Vianna, 2018) (SI Appendix, Methods). The debristo-food ratio implicitly assumes uniform mixing of plastic debris and food in the ocean, and that the higher likelihood of debris ingestion due to higher debris occurrence (Schuyler et al., 2016) results in more debris in the digestive system relative to food.

Ecological literature often expresses the influence of plastics on sea turtles in terms of the percentage of debris in digestive contents, $\% V_{\mathrm{dc}}$. Under the assumption that digestive capacity is indiscriminately occupied by both, we obtain the simplest relation between quantities $R, X / Y$, and $\% V_{\mathrm{dc}}$ :

$$
\frac{\% V_{\mathrm{dc}}}{1-\% V_{\mathrm{dc}}}=R \frac{Y}{X} \text {. }
$$

The simple form is intuitively appealing because either $Y / X=0$ or $R=0$ leads also to $\% V_{\mathrm{dc}}=0$, whereas either $Y / X \rightarrow \infty$ or $R \rightarrow \infty$ leads to $\% V_{\mathrm{dc}}=1$. In other words, debris in digestive contents is negligible in a plastics-poor environment or if the clearance of plastics is much faster than that of food. Conversely, debris overwhelms gastrointestinal tract in a plastics-rich environment or if the clearance of plastics is relatively slow. By using the percentage of debris in digestive contents as the target quantity for simulations, we bypass the uncertainties linked to preferential plastics ingestion of specific life stages, as well as different types of plastic debris having different residence times. The chances of debris ingestion and variability of residence time by the plastics types does not matter as long as relative abundance of ingested plastics remains reasonably constant. The simulated percentages in stomach contents have been truth-grounded against necropsy data (Frick et al., 2009; Lynch, 2018 ); presently, the mean and the maximum value of $\% V_{\mathrm{dc}}$ are $3 \%$ and $25 \%$, respectively (Frick et al., 2009).

Data Accessibility. The data associated with the paper has been made available via HAL (hal-02880223) and associated code via $\mathrm{GitHub}^{\dagger}$ and Add-my-Pet repository ${ }^{\ddagger}$.

ACKNOWLEDGMENTS. NM was supported by Unity Through Knowledge Fund (UKF) grant (no. 11/19). NM and TK were funded by the Croatian science foundation (HRZZ) project AqADAPT (no. IP-2018-01-3150). Authors thank P. Holme for logistic support, J. Lynch for sharing her database on sea turtle plastic ingestion, and the staff of the Pula Rehabilitation Center for sharing unpublished data.

Barnes, D. K. A., Galgani, F., Thompson, R. C., and Barlaz, M. (2009). Accumulation and fragmentation of plastic debris in global environments. Phil. Trans. R. Soc. B, 364(1526):1985-1998.

Batel, A., Linti, F., Scherer, M., Erdinger, L., and Braunbeck, T. (2016). Transfer of benzo [a] pyrene from microplastics to artemia nauplii and further to zebrafish via a trophic food web experiment: CYP1A induction and visual tracking of persistent organic pollutants. Environ. Toxicol. Chem. 35(7):1656-1666.

Beekman, M., Thompson, M., and Jusup, M. (2019). Thermodynamic constraints and the evolution of parental provisioning in vertebrates. Behav. Ecol., 30(3):583-591.

Campani, T., Baini, M., Giannetti, M., Cancelli, F., Mancusi, C., Serena, F., Marsili, L., Casini, S. and Fossi, M. C. (2013). Presence of plastic debris in loggerhead turtle stranded along the Tuscany coasts of the Pelagos Sanctuary for Mediterranean Marine Mammals (Italy). Mar. Pollut. Bull., 74(1):225-230.

Casale, P., Freggi, D., Paduano, V., and Oliverio, M. (2016). Biases and best approaches for assessing debris ingestion in sea turtles, with a case study in the mediterranean. Mar. Pollut. Bull., 110(1):238-249.

Clukey, K. E., Lepczyk, C. A., Balazs, G. H., Work, T. M., and Lynch, J. M. (2017). Investigation of plastic debris ingestion by four species of sea turtles collected as bycatch in pelagic Pacific longline fisheries. Mar. Pollut. Bull., 120(1):117-125.

Connors, P. G. and Smith, K. (1982). Oceanic plastic particle pollution: Suspected effect on fat deposition in red phalaropes. Mar. Pollut. Bull., 13(1):18-20.

Cozar, A., Echevarriaa, F., Gonzalez-Gordilloa, J. I., Irigoien, X., Ubeda, B., Hernandez-Leon, S. Palma, A. T., Navarrof, S., de Lomas, J. G., Ruiz, A., de Puelles, M. L. F., and Duarte, C. M. (2014). Plastic debris in the open ocean. Proc. Natl Acad. Sci. U.S.A., 111(28):10239-10244.

${ }^{\dagger}$ https://github.com/ninamarn/marineDebrisTurtle

${ }^{\ddagger}$ http://www.bio.vu.nl/thb/deb/deblab/add_my_pet/entries_web/Caretta_caretta/Caretta_caretta_ res.html
Cushman, S. A. (2006). Effects of habitat loss and fragmentation on amphibians: A review and prospectus. Biol. Conserv., 128(2):231-240.

De Roos, A. M. (2008). Demographic analysis of continuous-time life-history models. Ecol. Lett., 11(1):1-15.

De Roos, A. M. and Persson, L. (2002). Size-dependent life-history traits promote catastrophic collapses of top predators. Proc. Natl. Acad. Sci. USA, 99(20):12907-12912.

Derraik, J. G. B. (2002). The pollution of the marine environment by plastic debris: a review. Mar. Pollut. Bull., 44(9):842 - 852.

Diekmann, O., Gyllenberg, M., and Metz, J. (2003). Steady-state analysis of structured population models. Theor. Popul. Biol., 63(4):309-338.

Eriksen, M., Lebreton, L. C., Carson, H. S., Thiel, M., Moore, C. J., Borerro, J. C., Galgani, F., Ryan, P. G., and Reisser, J. (2014). Plastic pollution in the world's oceans: more than 5 trillion plastic pieces weighing over 250,000 tons afloat at sea. PLOS ONE, 9(12):e111913.

Figueiredo, G. M. and Vianna, T. M. P. (2018). Suspended microplastics in a highly polluted bay: Abundance, size, and availability for mesozooplankton. Mar. Pollut. Bull., 135:256-265.

Fossi, M. C., Pedà, C., Compa, M., Tsangaris, C., Alomar, C., Claro, F., loakeimidis, C., Galgani, F., Hema, T., Deudero, S., Romeo, T., Battaglia, P., Andaloro, F., Caliani, I., Casini, S., Panti, C., and Baini, M. (2018). Bioindicators for monitoring marine litter ingestion and its impacts on Mediterranean biodiversity. Environ. Pollut., 237:1023-1040.

Frick, M. G., Williams, K. L., Bolten, A. B., Bjorndal, K. A., and Martins, H. R. (2009). Foraging ecology of oceanic-stage loggerhead turtles caretta caretta. Endanger. Species Res., 9:91-97.

Fukuoka, T., Yamane, M., Kinoshita, C., Narazaki, T., Marshall, G. J., Abernathy, K. J., Miyazaki, N., and Sato, K. (2016). The feeding habit of sea turtles influences their reaction to artificial marine debris. Sci. Rep., 6:28015.

Galic, N., Sullivan, L., Grimm, V., and Forbes, V. (2018). When things don't add up: quantifying impacts of multiple stressors from individual metabolism to ecosystem processing. Ecol. Lett., 21(4):568-577.

Gall, S. and Thompson, R. (2015). The impact of debris on marine life. Mar. Pollut. Bull., 92(1):170179.

Gramentz, D. (1988). Involvement of loggerhead turtle with the plastic, metal, and hydrocarbon pollution in the central Mediterranean. Mar. Pollut. Bull., 19(1):11-13.

Hamann, M., Godfrey, M., Seminoff, J., Arthur, K., Barata, P., Bjorndal, K., Bolten, A., Broderick, A., Campbell, L., Carreras, C., Casale, P., Chaloupka, M., Chan, S., Coyne, M., Crowder, L., Diez, C., Dutton, P., Epperly, S., FitzSimmons, N., Formia, A., Girondot, M., Hays, G., Cheng, I., Kaska, Y., Lewison, R., Mortimer, J., Nichols, W., Reina, R., Shanker, K., Spotila, J., Tomás, J., Wallace, B., Work, T., Zbinden, J., and Godley, B. (2010). Global research priorities for sea turtles: informing management and conservation in the 21st century. Endanger. Species Res., 11(3):245-269.

Hawkes, L., Broderick, A., Godfrey, M., and Godley, B. (2005). Status of nesting loggerhead turtles Caretta caretta at Bald Head island (North Carolina, USA) after 24 years of intensive monitoring and conservation. Oryx, 39:65-72.

Heppell, S., Crowder, L., Crouse, D., S.P., E., and Frazer, N. (2003). Population models for atlantic loggerheads: Past, present, and future. In Bolten, A. and Witherington, B., editors, Loggerhead Sea Turtles, pages 255-273. Smithsonian Institution Press, Washington D.C.

ljima, H., Jusup, M., Takada, T., Akita, T., Matsuda, H., and Klanjscek, T. (2019). Effects of environmental change and early-life stochasticity on Pacific bluefin tuna population growth. Mar. Environ. Res., 149:18-26.

Jager, T., Heugens, E. H. W., and Kooijman, S. A. L. M. (2006). Making sense of ecotoxicological test results: Towards application of process-based models. Ecotoxicology, 15(3):305-314.

Jager, T. and Zimmer, E. I. (2012). Simplified dynamic energy budget model for analysing ecotoxicity data. Ecol. Model., 225:74-81.

Jambeck, J. R., Geyer, R., Wilcox, C., Siegler, T. R., Perryman, M., Andrady, A., Narayan, R., and Law, K. L. (2015). Plastic waste inputs from land into the ocean. Science, 347(6223):768-771.

Jusup, M., Sousa, T., Domingos, T., Labinac, V., Marn, N., Wang, Z., and Klanjšček, T. (2017). Physics of metabolic organization. Phys. Life Rev., 20:1-39.

Klanjscek, T., Caswell, H., Neubert, M. G., and Nisbet, R. M. (2006). Integrating dynamic energy budgets into matrix population models. Ecol. Model., 196(3-4):407-420.

Klanjscek, T., Nisbet, R. M., Caswell, H., and Neubert, M. G. (2007). A model for energetics and bioaccumulation in marine mammals with applications to the right whale. Ecol. Appl., 17(8):2233-2250.

Kramer, V. J., Etterson, M. A., Hecker, M., Murphy, C. A., Roesijadi, G., Spade, D. J., Spromberg J. A., Wang, M., and Ankley, G. T. (2011). Adverse outcome pathways and ecological risk assessment: Bridging to population-level effects. Environ. Toxicol. Chem., 30(1):64-76.

Lazar, B. and Gračan, R. (2011). Ingestion of marine debris by loggerhead sea turtles, caretta caretta, in the Adriatic sea. Mar. Pollut. Bull., 62(1):43-47.

Lebreton, L. C., Van der Zwet, J., Damsteeg, J.-W., Slat, B., Andrady, A., and Reisser, J. (2017) River plastic emissions to the world's oceans. Nat. Commun., 8:15611.

Lutz, P. (1990). Studies on the ingestion of plastic and latex by sea turtles. In Shomura, R. and Godfrey, M., editors, Proceedings of the Second International Conference on Marine Debris, pages $719-735$, Honolulu. US Dept. Commerce, NOAA Tech. Memo. NMFS, NOAA-TM-NMFSSWFS-154.

Lynch, J. M. (2018). Quantities of marine debris ingested by sea turtles: global meta-analysis highlights need for standardized data reporting methods and reveals relative risk. Environ. Sci. Technol., 52(21):12026-12038.

Marn, N., Jusup, M., Catteau, S., Kooijman, S., and Klanjšček, T. (2019). Comparative physiological energetics of Mediterranean and North Atlantic loggerhead turtles. J. Sea Res., 143:100-118.

Marn, N., Jusup, M., Legović, T., Kooijman, S., and Klanjšček, T. (2017a). Environmental effects on growth, reproduction, and life-history traits of loggerhead turtles. Ecol. Model., 360:163-178.

Marn, N., Kooijman, S., Jusup, M., Legović, T., and Klanjšček, T. (2017b). Inferring physiological energetics of loggerhead turtle (Caretta caretta) from existing data using a general metabolic theory. Mar. Environ. Res., 126:14-25.

Marques, G., Augustine, S., Lika, K., Pecquerie, L., Domingos, T., and Kooijman, S. (2018). The AmP project: Comparing species on the basis of dynamic energy budget parameters. PLOS Comput. Biol., 14(5):e1006100. 
593 Mascarenhas, R., Santos, R., and Zeppelini, D. (2004). Plastic debris ingestion by sea turtle in Paraíba, Brazil. Mar. Pollut. Bull., 49(4):354-355.

Mato, Y., Isobe, T., Takada, H., Kanehiro, H., Ohtake, C., and Kaminuma, T. (2001). Plastic resin pellets as a transport medium for toxic chemicals in the marine environment. Environ. Sci. Technol., 35(2):318-324.

Mazaris, A. D., Broder, B., and Matsinos, Y. G. (2006). An individual based model of a sea turtle population to analyze effects of age dependent mortality. Ecol. Model., 198(1-2):174-182.

McCauley, S. J. and Bjorndal, K. A. (1999). Conservation implication of dietary dilution from debris ingestion: sublethal effects in post-hatchling loggerhead sea turtles. Conserv. Biol., 13(4):925929.

Moore, C. (2008). Synthetic polymers in the marine environment: a rapidly increasing, long-term threat. Environ. Res., 108(2):131-139.

Moore, C., Moore, S., Leecaster, M., and Weisberg, S. (2001). A comparison of plastic and plankton in the North Pacific central gyre. Mar. Pollut. Bull., 42(12):1297-1300.

Narazaki, T., Sato, K., Abernathy, K. J., Marshall, G. J., and Miyazaki, N. (2013). Loggerhead turtles (Caretta caretta) use vision to forage on gelatinous prey in mid-water. PLOS ONE, 8(6):e66043.

Nash, R. D., Valencia, A. H., and Geffen, A. J. (2006). The origin of Fulton's condition factor-setting the record straight. Fisheries, 31(5):236-238.

Nelms, S. E., Duncan, E. M., Broderick, A. C., Galloway, T. S., Godfrey, M. H., Hamann, M., Lindeque, P. K., and Godley, B. J. (2016). Plastic and marine turtles: a review and call for research. ICES J. Mar. Sci., 73(2):165-181.

Nisbet, R., Muller, E., Lika, K., and Kooijman, S. (2000). From molecules to ecosystems through Dynamic Energy Budget models. J. Anim. Ecol., 69(6):913-926.

Nisbet, R. M., Jusup, M., Klanjscek, T., and Pecquerie, L. (2012). Integrating dynamic energy budget (DEB) theory with traditional bioenergetic models. J. Exp. Biol., 215(6):892-902.

Pham, C. K., Rodríguez, Y., Dauphin, A., Carriço, R., Frias, J. P., Vandeperre, F., Otero, V., Santos, M. R., Martins, H. R., Bolten, A. B., et al. (2017). Plastic ingestion in oceanic-stage loggerhead sea turtles (Caretta caretta) off the (north atlantic) subtropical gyre. Mar. Pollut. Bull., 121(1. 2):222-229.

Rezania, S., Park, J., Din, M. F. M., Taib, S. M., Talaiekhozani, A., Yadav, K. K., and Kamyab, H. (2018). Microplastics pollution in different aquatic environments and biota: A review of recent studies. Mar. Pollut. Bull., 133:191-208.

Rochman, C. M., Tahir, A., Williams, S. L., Baxa, D. V., Lam, R., Miller, J. T., Teh, F.-C., Werorilangi, S., and Teh, S. J. (2015). Anthropogenic debris in seafood: Plastic debris and fibers from textiles in fish and bivalves sold for human consumption. Sci. Rep., 5:e14340.

Ryan, P. (1988). Effects of ingested plastic on seabird feeding: Evidence from chickens. Mar. Pollut. Bull., 19(3):125-128

Ryan, P. G., Cole, G., Spiby, K., Nel, R., Osborne, A., and Perold, V. (2016). Impacts of plastic ingestion on post-hatchling loggerhead turtles off South Africa. Mar. Pollut. Bull., 107(1):155160.

Santos, R. G., Andrades, R., Boldrini, M. A., and Martins, A. S. (2015). Debris ingestion by juvenile marine turtles: An underestimated problem. Mar. Pollut. Bull., 93(1):37-43.

Sasso, C. R., Braun-McNeill, J., Avens, L., and Epperly, S. P. (2006). Effects of transients on estimating survival and population growth in juvenile loggerhead turtles. Mar. Ecol. Prog. Ser., 324:287-292.

Schuyler, Q., Hardesty, B. D., Wilcox, C., and Townsend, K. (2012). To eat or not to eat? Debris selectivity by marine turtles. PLOS ONE, 7(7).

Schuyler, Q., Hardesty, B. D., Wilcox, C., and Townsend, K. (2014a). Global analysis of anthropogenic debris ingestion by sea turtles. Conserv. Biol., 28:129-139.

Schuyler, Q. A., Wilcox, C., Townsend, K., Hardesty, B. D., and Marshall, N. J. (2014b). Mistaken identity? Visual similarities of marine debris to natural prey items of sea turtles. BMC Ecol., 14(1):14.

Schuyler, Q. A., Wilcox, C., Townsend, K. A., Wedemeyer-Strombel, K. R., Balazs, G., Sebille, E., and Hardesty, B. D. (2016). Risk analysis reveals global hotspots for marine debris ingestion by sea turtles. Glob. Change Biol., 22(2):567-576.

Smallegange, I. M., Caswell, H., Toorians, M. E., and de Roos, A. M. (2017). Mechanistic description of population dynamics using dynamic energy budget theory incorporated into integral projection models. Methods Ecol. Evol., 8(2):146-154.

Sousa, T., Domingos, T., and Kooijman, S. (2008). From empirical patterns to theory: A formal metabolic theory of life. Phil. Trans. R. Soc. B, 363(1502):2453-2464.

Sousa, T., Domingos, T., Poggiale, J.-C., and Kooijman, S. (2010). Dynamic Energy Budget theory restores coherence in biology. Phil. Trans. R. Soc. B, 365(1557):3413-3428.

Stahelin, G. D., Hennemann, M. C., Cegoni, C. T., Wanderlinde, J., e Lima, E. P., and Goldberg, D. W. (2012). Case report: Ingestion of a massive amount of debris by a green turtle (Chelonia mydas) in Southern Brazil. Mar. Turt. Newsl., 135:6-8.

Stubbs, J. L., Marn, N., Vanderklift, M. A., Fossette, S., and Mitchell, N. J. (2020). Simulated growth and reproduction of green turtles (Chelonia mydas) under climate change and marine heatwave scenarios. Ecol. Model., in press. accepted for publication June 2020.

Thompson, R. C., Olsen, Y., Mitchell, R. P., Davis, A., Rowland, S. J., John, A. W. G., McGonigle, D., and Russell, A. E. (2004). Lost at sea: Where is all the plastic? Science, 304(5672):838.

Thompson, R. C., Swan, S. H., Moore, C. J., and vom Saal, F. S. (2009). Our plastic age. Phil. Trans. R. Soc. B, 364:1973-1976.

Tiwari, M. and Bjorndal, K. A. (2000). Variation in morphology and reproduction in loggerheads, Caretta caretta, nesting in the United States, Brazil, and Greece. Herpetologica, 56(3):343356.

Tomás, J., Guitart, R., Mateo, R., and Raga, J. (2002). Marine debris ingestion in loggerhead sea turtles, caretta caretta, from the Western Mediterranean. Mar. Pollut. Bull., 44(3):211-216.

Tucker, A. D. (2010). Nest site fidelity and clutch frequency of loggerhead turtles are better elucidated by satellite telemetry than by nocturnal tagging efforts: Implications for stock estimation. J. Exp. Mar. Biol. Ecol., 383(1):48-55.

Valente, A., Marco, I., Parga, M., Lavin, S., Alegre, F., and Cuenca, R. (2008). Ingesta passage and gastric emptying times in loggerhead sea turtles (Caretta caretta). Res. Vet. Sci., 84(1):132139.

van Leeuwen, I. M., Vera, J., and Wolkenhauer, O. (2010). Dynamic energy budget approaches for modelling organismal ageing. Philos. Trans. R. Soc. B, 365(1557):3443-3454.

Wallace, B. P., DiMatteo, A. D., Bolten, A. B., Chaloupka, M. Y., Hutchinson, B. J., Abreu-Grobois, F. A., Mortimer, J. A., Seminoff, J. A., Amorocho, D., Bjorndal, K. A., Bourjea, J., Bowen, B. W., Duenas, R. B., Choudhury, B. C., Costa, A., Dutton, P. H., Fallabrino, A., Casale, P., Girondot, M., Hamann, M., Hurley, B. J., Finkbeiner, E. M., Girard, A., Lopez-Mendilaharsu, M., Marcovaldi, M. A., Musick, J. A., Nel, R., Pilcher, N. J., Troeng, S., Witherington, B., and Mast, R. B. (2011). Global conservation priorities for marine turtle. PLOS ONE, 6:e24510.

Wilcox, C., Puckridge, M., Schuyler, Q. A., Townsend, K., and Hardesty, B. D. (2018). A quantitative analysis linking sea turtle mortality and plastic debris ingestion. Sci. Rep., 8:12536.

Yamashita, R., Takada, H., aki Fukuwaka, M., and Watanuki, Y. (2011). Physical and chemical effects of ingested plastic debris on short-tailed shearwaters, puffinus tenuirostris, in the North Pacific Ocean. Mar. Pollut. Bull., 62(12):2845-2849.

Zug, G. R., Wynn, A. H., and Ruckdeschel, C. (1986). Age determination of loggerhead sea turtles, Caretta caretta, by incremental growth marks in the skeleton. Smithson. Contr. Zool., 427. 


\section{Supplementary Information for}

. Quantifying impacts of plastic debris on marine wildlife identifies ecological breakpoints

4 Nina Marn, Marko Jusup, S.A.L.M. Kooijman, and Tin Klanjscek

5 E-mail: nmarn@irb.hr (NM)

6 E-mail: tin@irb.hr (TK)

7. This PDF file includes:

Figs. S1 to S6

References for SI reference citations 
Supporting Methods

Model equations for ontogenetic development. To simulate realistic ontogenies of individual sea turtles, we relied on physiological energetics, and specifically the standard Dynamic Energy Budget (DEB) model (Sousa et al., 2008, 2010; Kooijman, 2010; Jusup et al., 2017) (Fig. S1). This model traces the individual's state -its size, life stage, and condition ( $i$-state variables) - as a function of age, depending on physiological characteristics that are mirrored in the values of the model parameters. The environmental conditions, such as food abundance and temperature, act as forcing variables (e-state variables).

The rates of change of a sea turtle's $i$-state variables are given by a set of three differential equations. Eq. (1) for length $L$ (in $\mathrm{cm}$ ) tracks energy used for growth, Eq. (2) for life-stage indicator $E_{H}$ (in $J$ ) tracks cumulative energy invested into maturation, and Eq. (3) for condition $E$ (in $J$ ) tracks the amount of available energy reserve:

$$
\begin{aligned}
\frac{\mathrm{d} L}{\mathrm{~d} t} & =\frac{\dot{p}_{G}}{3 L^{2}\left[E_{G}\right]}, \\
\frac{\mathrm{d} E_{H}}{\mathrm{~d} t} & =\left\{\begin{array}{ll}
\dot{p}_{R} & \text { if } E_{H}<E_{H}^{p}, \\
0 & \text { otherwise }
\end{array},\right. \text { and } \\
\frac{\mathrm{d} E}{\mathrm{~d} t} & =\dot{p}_{A}-\dot{p}_{C},
\end{aligned}
$$

where $\left[E_{G}\right]\left(\right.$ in $\mathrm{J} \mathrm{cm}^{-3}$ ) is the volume-specific cost for growth, and $E_{H}^{p}$ (in $\mathrm{J}$ ) is threshold maturity for sexual maturation. Length $L$ is not a measurable quantity itself, but connects to often measured straight carapace length $L_{\mathrm{SCL}}$ via shape factor $\delta_{\mathrm{SCL}}$, i.e., $L=L_{\mathrm{SCL}} \delta_{\mathrm{SCL}}$. Below, we define energy flows $\dot{p}_{*}\left(\right.$ in $\left.\mathrm{J} \mathrm{d}^{-1}\right)$ in terms of $i$-state variables. A sea turtle acquires energy through assimilation:

$$
\dot{p}_{A}=\left\{\dot{p}_{A m}\right\} L^{2} f,
$$

where the performance of the turtle's digestive system is reflected in the surface-specific maximum assimilation rate, $\left\{\dot{p}_{A m}\right\}$ (in $\mathrm{J} \mathrm{d}^{-1} \mathrm{~cm}^{-2}$ ), while food abundance $f, 0 \leq f<1$, is the ratio of the current ingestion rate to the maximum ingestion rate at unlimited food supply. Assimilated energy gets mobilized from reserve to power metabolic processes at a rate determined by the utilization energy flow:

$$
\dot{p}_{C}=[E] \frac{\dot{v}\left[E_{G}\right] L^{2}+\left[\dot{p}_{M}\right] L^{3}}{\left[E_{G}\right]+\kappa[E]},
$$

where $[E]=E / L^{3}$ is energy reserve density, parameter $\dot{v}\left(\right.$ in $\mathrm{cm} \mathrm{d}^{-1}$ ) is energy conductance, and dimensionless parameter $\kappa, 0<\kappa<1$, is a fraction of utilization flow directed to somatic maintenance and growth. Finally, the sea turtle grows at a rate:

$$
\dot{p}_{G}=\left[E_{G}\right] \frac{\kappa \dot{v}[E] L^{2}-\left[\dot{p}_{M}\right] L^{3}}{\left[E_{G}\right]+\kappa[E]},
$$

provided there is mobilized energy left after satisfying the somatic maintenance needs, i.e., $\kappa \dot{p}_{C}>\left[\dot{p}_{M}\right] L^{3}$.

As indicated, fraction $\kappa \dot{p}_{C}$ of mobilized energy is used for somatic maintenance and growth, while the remaining fraction, $(1-\kappa) \dot{p}_{C}$, is allocated to maturation in embryo and juveniles, and to reproduction in adults: $\dot{p}_{R}=$ $(1-\kappa) \dot{p}_{C}-\dot{k}_{J} E_{H}$, where $\dot{k}_{J}$ (in $\mathrm{d}^{-1}$ ) is the maturity maintenance coefficient. Life-stage transitions from embryo to juvenile, and from juvenile to adult, occur at maturity thresholds $E_{H}^{b}$ and $E_{H}^{p}$, respectively. Investment into reproduction starts after puberty $\left(E_{H}^{p}\right)$ and determines fecundity in adults: $\dot{F}=\kappa_{R} \dot{p}_{R} / E_{0}$, where dimensionless parameter $\kappa_{R}$ is the efficiency of energy conversion from reserve to eggs, and $E_{0}$ (in $\mathrm{J}$ ) is the energetic value of an egg. Fig. S2 visualizes the energy allocation of a free-ranging loggerhead turtle experiencing food abundance $f=0.81$.

In the described frameworks, body mass is not an $i$-state variable, but rather a function of length $L$, reserve $E$, and energy $E_{R}$ stored for reproduction between two nesting seasons. Quantity $E_{R}$ is calculated only for adult individuals using $E_{R}=\int \dot{p}_{R} \mathrm{~d} t$, where integration is performed over predominantly biannual remigration period (Hawkes et al., 2005). Body mass is calculated as:

$$
W=d_{V} L^{3}+\rho_{E}\left(E+E_{R}\right),
$$

where $d_{V} \approx 1 \mathrm{~g} \mathrm{~cm}^{-3}$ is body density and $\rho_{E}\left(\right.$ in $\left.\mathrm{g} \mathrm{J}^{-1}\right)$ is a mass-energy coupler for reserve. The second term in this equation indicates the animal's condition, which is best seen through the connection with Fulton's condition factor (Nash et al., 2006):

$$
\mathrm{CF} \propto \frac{W}{L_{\mathrm{SCL}}^{3}}=d_{V} \delta_{\mathrm{SCL}}^{3}+\rho_{E} \frac{E+E_{R}}{L_{\mathrm{SCL}}^{3}} .
$$

The proportionality constant is $C_{0}=100 \mathrm{~cm}^{3} \mathrm{~g}^{-1}$ if wet body mass is expressed in grams and straight carapace length in centimeters. 


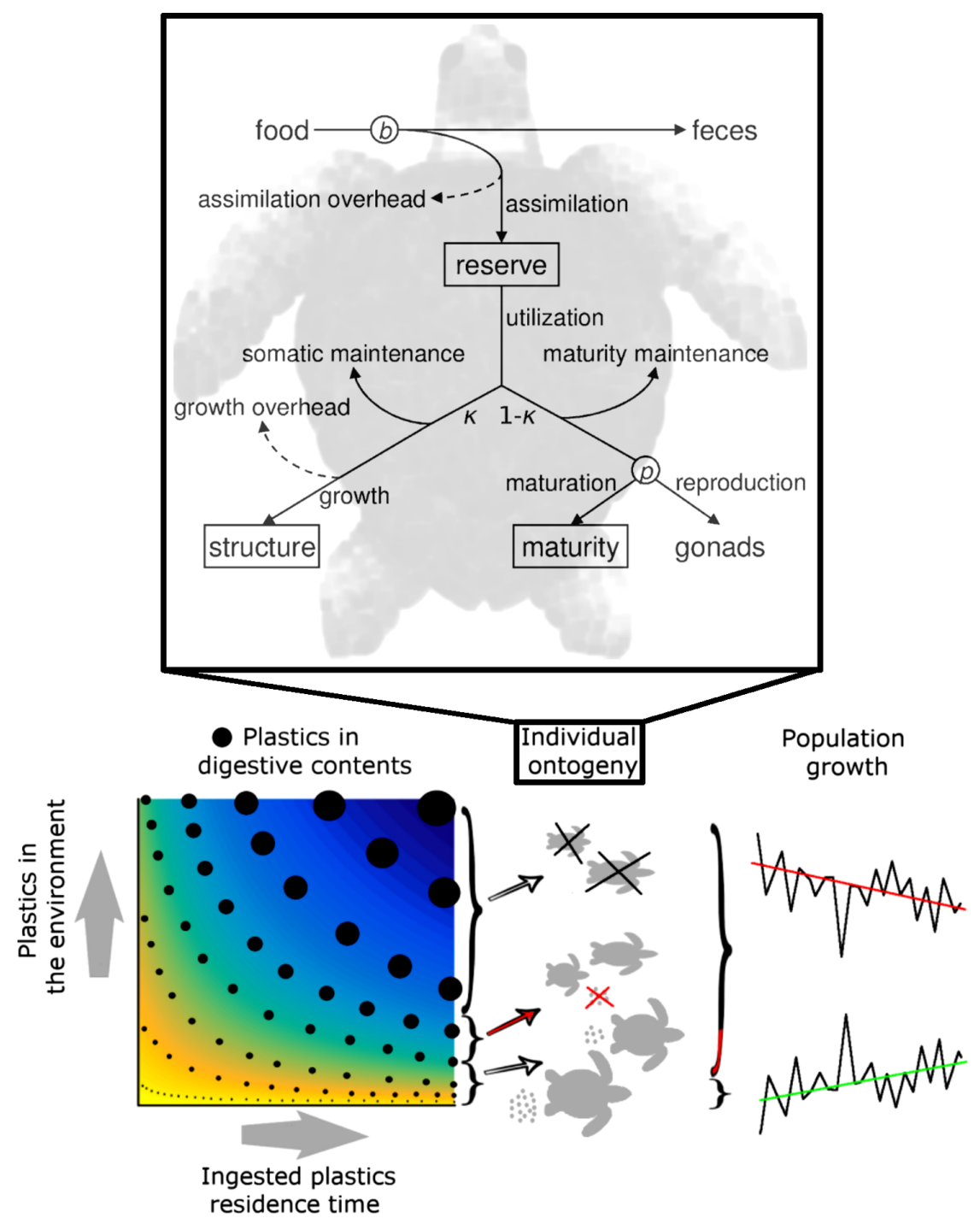

Fig. S1. Schematic representation of the proposed modeling framework. More plastic debris in the environment or a longer ingested-plastics residence time result in more of the digestive capacity being occupied by plastics instead of food. This affects individual ontogeny by reducing the energy assimilated into reserve, and thereafter the energy available for growth and maturation (or reproduction) after all maintenance costs are paid. In response, individuals may grow smaller, their condition may decrease, they may lose the ability to reproduce, and they may even die under the most extreme circumstances. At the population level, moreover, reproducing individuals are no guarantee of positive growth because fecundity may be insufficient to compensate for mortality losses, in which case the population declines. Individual ontogeny depending on the state of the environment and the state of the individual is captured using the standard Dynamic Energy Budget model (box), but with parameter values adjusted to loggerhead turtles.

Model parameters and the generality of physiological energetics. The values of model parameters pertaining to the North Atlantic population of loggerhead turtles at the temperature of $21.8^{\circ} \mathrm{C}$ are: $\left[E_{G}\right]=7322 \mathrm{~J} \mathrm{~cm}^{-3}, E_{H}^{b}=$ $2.535 \cdot 10^{4} \mathrm{~J}, E_{H}^{p}=9.875 \cdot 10^{7} \mathrm{~J},\left\{\dot{p}_{A m}\right\}=868.11 \mathrm{~J} \mathrm{~cm}^{-2}, \dot{v}=0.0791 \mathrm{~cm} \mathrm{~d}^{-1},\left[\dot{p}_{M}\right]=13.01 \mathrm{~J} \mathrm{~cm}^{-3}, \dot{k}_{J}=0.0013 \mathrm{~d}^{-1}$, $\kappa=0.729, \kappa_{R}=0.95, \delta_{\mathrm{SCL}}=0.39, E_{0}=178.56 \mathrm{~kJ}$, and $\rho_{E}=1.552 \cdot 10^{4} \mathrm{~g} \mathrm{~J}^{-1}$ (Marn et al., 2017b). Data from all life stages used to calibrate the model, as well as the potential updates to model parameters, are freely accessible in the Add-my-Pet collection* (Marques et al., 2018). A discussion on the model calibration and model predictions in the context of the reported values for North Atlantic loggerhead turtles, including inter-individual variability in growth, maturation, and reproduction due to experienced food abundance and temperature, are available in the literature (Marn et al., 2017b,a). We deliberately decided to work with model parameters pertaining to the North Atlantic population of loggerhead turtles, but other populations or species from the Add-my-Pet collection, e.g., the Mediterranean population of loggerhead turtles (Marn et al., 2019), green turtles (Stubbs et al., 2019), or any other species exposed to plastics ingestion would have been equally acceptable. Testifying to the generality of the approach is the fact that the Add-my-Pet collection currently contains over 2000 entries.

*https://www.bio.vu.nl/thb/deb/deblab/add_my_pet 


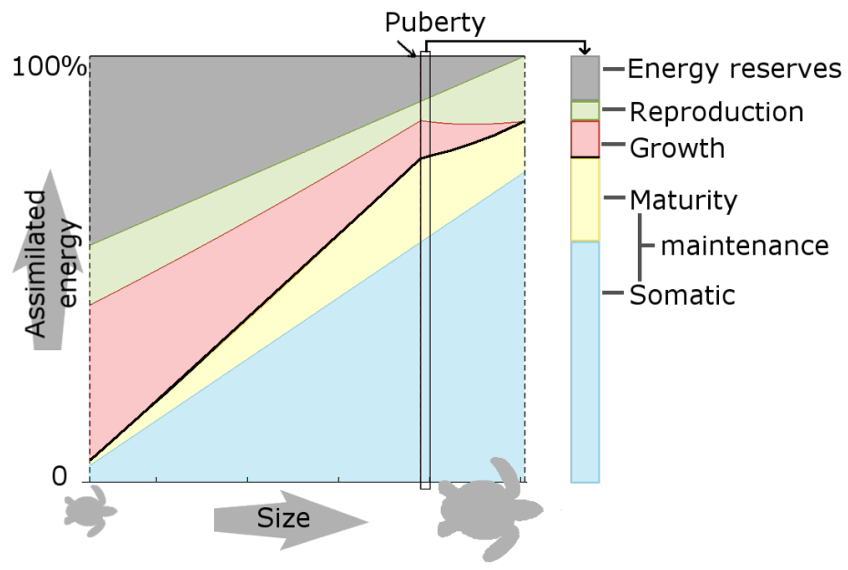

Fig. S2. Energy budget of a loggerhead turtle throughout its ontogeny. Shown is the allocation of assimilated energy to main ontogenetic processes: maintenance, growth, maturation or reproduction, and reserve buildup. Further emphasized is a snapshot of the energy budget at sexual maturation. Maintenance demands are sizedriven, leaving large turtles with less energy for growing and accumulating reserve. Investment into maturation halts when turtles sexually mature. Instead, investment into reproduction begins. Here, food abundance is set to $f=0.81$, corresponding to what free-ranging loggerhead turtles experience in the wild.

Plastic ingestion and effective food abundance. Food abundance $f$ introduced in Eq. (4) depends on food density in the environment, $X$ (in $\mathrm{g} \mathrm{dm}^{-3}$ ), via the Holling type-II functional response (Holling, 1959):

$$
f=\frac{X}{X+K_{X}} .
$$

Here, $K_{X}$ (in $\mathrm{g} \mathrm{dm}^{-3}$ ) is the half-saturation constant for food. Relatively small $K_{X}$ characterizes animals with low ingestion demands and/or fast foraging rate, and such animals reach near-satiation at low food densities. The opposite holds for relatively large $K_{X}$.

In the presence of debris in the environment, the animal's effective half-saturation constant $K_{\text {eff }}$ becomes larger than $K_{X}$. Specifically, if $Y$ (in $\mathrm{g} \mathrm{dm}^{-3}$ ) denotes environmental debris density, then the relationship between $K_{\text {eff }}$ and $K_{X}$ is:

$$
K_{\mathrm{eff}}=K_{X}\left(1+\frac{Y}{K_{Y}}\right),
$$

where $K_{Y}$ is a debris analogue of the half-saturation constant. The animal thus perceives food abundance $f_{\text {eff }}=$ $X /\left(X+K_{\text {eff }}\right)$ that is lower than $f$ whenever $Y>0$. Below, we derive Eq. (10) via the competition of food and plastics for the limited digestive capacity of gastrointestinal tract.

Digestive capacity. Inspired by the concept of Synthesizing Units (Kooijman, 1998, 2006), we modeled energy uptake by assuming that ingested food and debris compete for the limited digestive capacity of the gastrointestinal tract. Parts of the capacity are either: (i) occupied by food, (ii) occupied by plastics, or (iii) free (unoccupied), which we respectively denote with fractions $\theta_{X}, \theta_{Y}$, and $\theta_{-}$. By definition $\theta_{X}+\theta_{Y}+\theta_{-}=1$. The dynamics of digestive capacity is determined by a binding rate $\left(\dot{b}_{i}\right.$ in $\left.\mathrm{dm}^{3} \mathrm{~g}^{-1} \mathrm{~d}^{-1}\right)$, and a release rate $\left(\dot{k}_{i}\right.$ in $\left.\mathrm{d}^{-1}\right)$, where $i=X$ for food or $i=Y$ for debris. The ratio of the two rates gives the half-saturation constant: $K_{i}=\dot{k}_{i} / \dot{b}_{i}$. The dynamics of the three fractions can then be written as a set of three ordinary differential equations (ODEs):

\begin{tabular}{cc|cc} 
Dynamics & Eq. & Equilibrium densities & Eq. \\
\hline$\frac{\mathrm{d} \theta_{X}}{\mathrm{~d} t}=\dot{b}_{X} \theta-X-\dot{k}_{X} \theta_{X}$ & [d1] & $\theta_{X}^{*}=\theta_{-}^{*} \frac{X}{K_{X}}$ & [e1] \\
\hline$\frac{\mathrm{d} \theta_{Y}}{\mathrm{~d} t}=\dot{b}_{Y} \theta_{-} Y-\dot{k}_{Y} \theta_{Y}$ & [d2] & $\theta_{Y}^{*}=\theta_{-}^{*} \frac{Y}{K_{Y}}$ & {$[\mathrm{e} 2]$} \\
\hline$\frac{\mathrm{d} \theta_{-}}{\mathrm{d} t}=-\dot{b}_{X} \theta-X+\dot{k}_{X} \theta_{X}-\dot{b}_{Y} \theta-Y+\dot{k}_{Y} \theta_{Y}$ & {$[\mathrm{~d} 3]$} & $\theta_{-}^{*}=\left(1+\frac{X}{K_{X}}+\frac{Y}{K_{Y}}\right)^{-1}$ & {$[\mathrm{e} 3]$} \\
\hline
\end{tabular}

The equilibrium digestive capacity fractions are marked with an asterisk.

Only the occupied part of the digestive capacity is responsible for energy assimilation. Analogously to Eq. (4), we have: $\dot{p}_{\mathrm{A}}=\left\{\dot{p}_{A m}\right\} L^{2}\left(\theta_{X}^{*}+\kappa_{Y} \theta_{Y}^{*}\right)$, where $\kappa_{Y}, 0 \leq \kappa_{Y}<1$, quantifies the energetic contribution of debris $(Y)$ relative food $(X)$. The effective food abundance is $f_{\text {eff }}=\theta_{X}^{*}+\kappa_{Y} \theta_{Y}^{*}$. Assuming debris has no energetic value, $\kappa_{Y}=0$. 
Inserting Eq. (e3) into Eq. (e1) finally yields:

$$
f_{\mathrm{eff}}=\theta_{X}^{*}=\frac{X}{X+K_{X}\left(1+\frac{Y}{K_{Y}}\right)},
$$

from where it becomes obvious that $K_{\text {eff }}=K_{X}\left(1+Y / K_{Y}\right)$ as specified in Eq. (10).

Comparing Eq. (9) and Eq. (11) leads to $f_{\text {eff }}=f /\left(1+f \frac{K_{X}}{K_{Y}} \frac{Y}{X}\right)$. Here, $Y / X$ is an environmental debris-to-food ratio. The ratio of half-saturation constants, $K_{X} / K_{Y}$, is best understood as follows. Because digestive capacity is indiscriminately occupied by food and debris, we have $\dot{b}_{X}=\dot{b}_{Y}$. We also have $\dot{k}_{X}>\dot{k}_{Y}$ because plastics is more inert than food. Accordingly, quantity $R=\frac{K_{X}}{K_{Y}}=\frac{\dot{k}_{X}}{\dot{k}_{Y}}>1$ is a ratio of clearance rates for food and plastics that shows how much longer plastics occupy digestive capacity relative to food. Existing literature, in line with inequality $R>1$, posits that it takes more time to egest plastics than digested food (Lutz, 1990; Mascarenhas et al., 2004; Valente et al., 2008). We finally arrive at an expression that relates food abundance $f$ in the absence of plastics to effective food abundance $f_{\text {eff }}$ in the presence of plastics:

$$
f_{\text {eff }}=\frac{f}{1+f R \frac{Y}{X}}
$$

Plastics in digestive contents. We have shown in Eq. (12) that effective food abundance in the presence of plastics is critically determined by two dimensionless factors: (i) the environmental debris-to-food ratio, $Y / X$, and (ii) the residence time of debris relative to food, $R$. The former factor quantifies the prevalence of debris in the environment, while the latter factor quantifies how much longer debris stays in the gastrointestinal tract relative to food. Although some indications of environmental debris prevalence and the relative debris residence time exist in the literature (Lutz, 1990; Moore et al., 2001; Mascarenhas et al., 2004; Valente et al., 2008; Barnes et al., 2009; Figueiredo and Vianna, 2018), field ecologists often measure the proportion of debris in digestive contents, $\% V_{\text {dc }}$ (Frick et al., 2009; Clukey et al., 2017; Lynch, 2018). To use available data in a consistent way, we need to establish a relationship between quantities $Y / X, R$, and $\% V_{\mathrm{dc}}$, while satisfying several constraints. First, if $Y \ll X$ then the presence of plastics is negligible and $\% V_{\mathrm{dc}} \rightarrow 0$, whereas if $Y \gg X$, the presence of plastics is overwhelming and $\% V_{\mathrm{dc}} \rightarrow 1$. Similarly, if $R \ll 1$ then plastics is quickly cleared from the gastrointestinal tract and $\% V_{\mathrm{dc}} \rightarrow 0$, whereas if $R \gg 1$ then plastics bioaccumulate in the gastrointestinal tract and $\% V_{\mathrm{dc}} \rightarrow 1$. The simplest relationship that satisfies these constraints is (Fig. S3):

$$
\frac{\% V_{\mathrm{dc}}}{1-\% V_{\mathrm{dc}}}=R \frac{Y}{X}
$$

Based on the known residence times of food from 9 to 13 days (Valente et al., 2008), and of debris from several weeks to several months (Lutz, 1990; Mascarenhas et al., 2004), we simulated relative debris residence times as the ratio of debris and food residence times in the range between $1 \leq R \leq 10$. The values of the environmental debris-to-food ratio are unknown at present for sea turtles, but in some areas more plastic particles than plankton have been observed (Moore et al., 2001) implying $Y / X>1$; in simulations we always varied $Y / X$ sufficiently to reach or even exceed the point at which individuals are unable to sexually mature. The different combinations of $R$ and $Y / X$ result in a range of $\% V_{\mathrm{dc}}$ values (Fig. S3) and thus effective food abundances illustrated in Fig. 1 of the main text. 


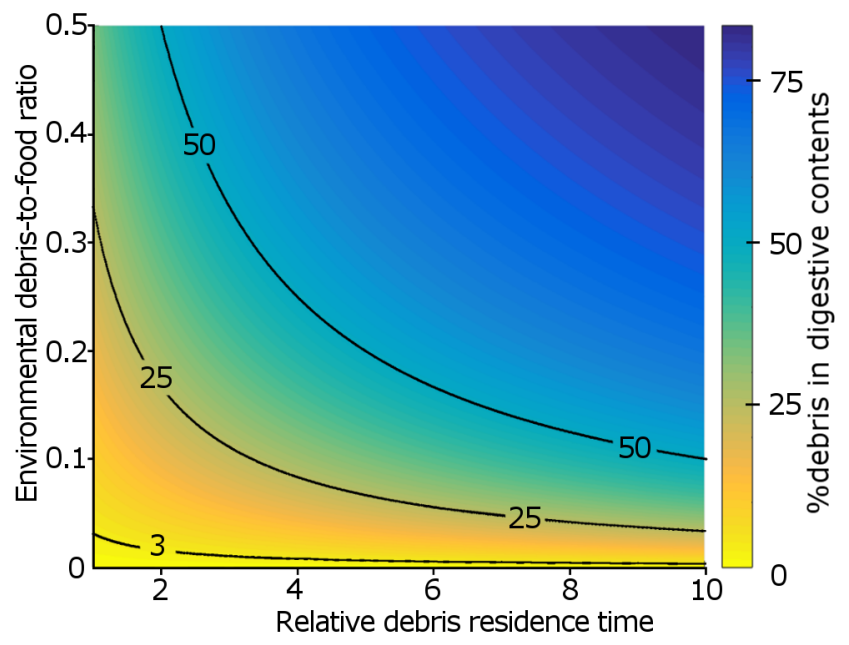

Fig. S3. Environmental debris-to-food ratio and relative debris residence time control the proportion of debris in digestive contents. Shown is the percentage debris in digestive contents, $\% V_{\mathrm{dc}}$ (colormap), as a function of debris-to-food ratio in the environment, $Y / X$ ( $\mathrm{y}$-axis), and the residence time of food relative to ingested debris, $R$ (x-axis). The representative values of $Y / X$ are currently unknown. We estimated the representative values of $R, 1.25 \leq R \leq 10$, based on the known residence times of food and debris in gastrointestinal tract of loggerheads (Lutz, 1990; Mascarenhas et al., 2004; Valente et al., 2008). The displayed range of \% $V_{\text {dc }}$ values between $0 \leq \% V_{\mathrm{dc}}<84 \%$ is illustrative and exceeds the range used in simulations. Of note is that existing data on plastics loads are plagued by uncertainties. For North Atlantic loggerhead turtles, the mean and the maximum reported percentage of plastics in stomach contents equals $3.2 \%$ and $25.7 \%$, respectively (Frick et al., 2009), yet the stomach is unlikely to be representative of the whole gastrointestinal tract in which ingested debris may bioaccumulate (Tomás et al., 2002; Campani et al., 2013). Measuring (i) debris in digestive contents and (ii) relative residence times, and then inverting the map shown here, may quantitatively constrain the presently unknown bio-availability of plastics to sea turtles.

\section{Supplementary Results}

Supplementary Result 1. Turtles exposed to plastics are expected to have lower condition than comparably sized unexposed turtles. Based on Eq. (8), for example, we predict a North Atlantic loggerhead juvenile of $40 \mathrm{~cm}$ straight carapace length at effective food abundance of $f_{\text {eff }}=0.64$ to have condition factor of $\mathrm{CF} \approx 12$. A similarly sized juvenile at food abundance of $f=0.81$ for unexposed loggerheads is expected to have a condition factor of $\mathrm{CF} \approx 14$. This difference in condition factors corresponds to $\approx 11 \%$ less body mass for exposed turtles relative to unexposed ones, which in turn corresponds to $\approx 19 \%$ less reserve because the difference in body mass is entirely due to less accumulated reserve. Available data, albeit limited, seem to support the model's prediction (Fig. S4). Specifically, we obtained from the Pula aquarium in Croatia sufficient information to estimate the condition factor of 77 loggerhead turtles, of which 8 individuals have been found to have ingested plastics. The average condition of exposed turtles is indeed lower by close to the predicted amount. However, more data is needed to establish statistical significance with sufficient power; the small number of exposed turtles may cause type II error with a large probability.

Supplementary Result 2. In the main text, we simplified simulations by assuming a constant exposure to plastics. A more realistic scenario is that sea turtles experience a time-varying environment such that the periods of no exposure interchange with the periods of potentially high exposure. To explore such a scenario, we performed additional simulations in which the proportion of debris in digestive contents, $\% V_{\mathrm{dc}}$, is $\log$-normally distributed with parameters $\mu=0.6$ and $\sigma=1.0$ (Fig. S5A). This generates a realistic mean of $\% V_{\mathrm{dc}} \approx 3 \%$, covers a realistic range of plastics loads between zero and $30 \%$, and mostly the load is low to moderate, with only occasional spikes (Fig. S5B) just as reported in the literature (Frick et al., 2009; Schuyler et al., 2014; Clukey et al., 2017; Lynch, 2018).

Based on the assumed distribution for the proportion of debris in digestive contents, we calculated new effective food abundance experienced by sea turtles every 30 simulation days and performed smooth interpolation for days in between. Spikes in plastics load were large enough to make effective food abundance occasionally insufficient to satisfy the basic maintenance needs, i.e., the animal could enter starvation. The formal condition for starvation is $\kappa \dot{p}_{C}<\left[\dot{p}_{M}\right] L^{3}$, from which point the energy deficit is compensated for by draining the energy stored for reproduction ( $i$-state variable $E_{R}$ ). If such energy is unavailable, the animal satisfies only the basic maintenance needs from reserve ( $i$-state variable $E$ ). In the latter case, Eq. (5) no longer holds, and instead $\dot{p}_{C}=\left[\dot{p}_{M}\right] L^{3}+\dot{k}_{J} E_{H}$. We assumed biannual reproduction (Hawkes et al., 2005) during which variable $E_{R}$ is emptied until there is not enough energy to produce a whole egg. The average energetic value of an egg calculated by the model equals $178.56 \mathrm{~kJ}$, and is close to that reported in literature (Hays and Speakman (1991)). The predicted reproductive output is expressed for the whole season as, for example, 600 eggs - in reality this would correspond to between 4 and 5 clutches (Tucker, 2010) 


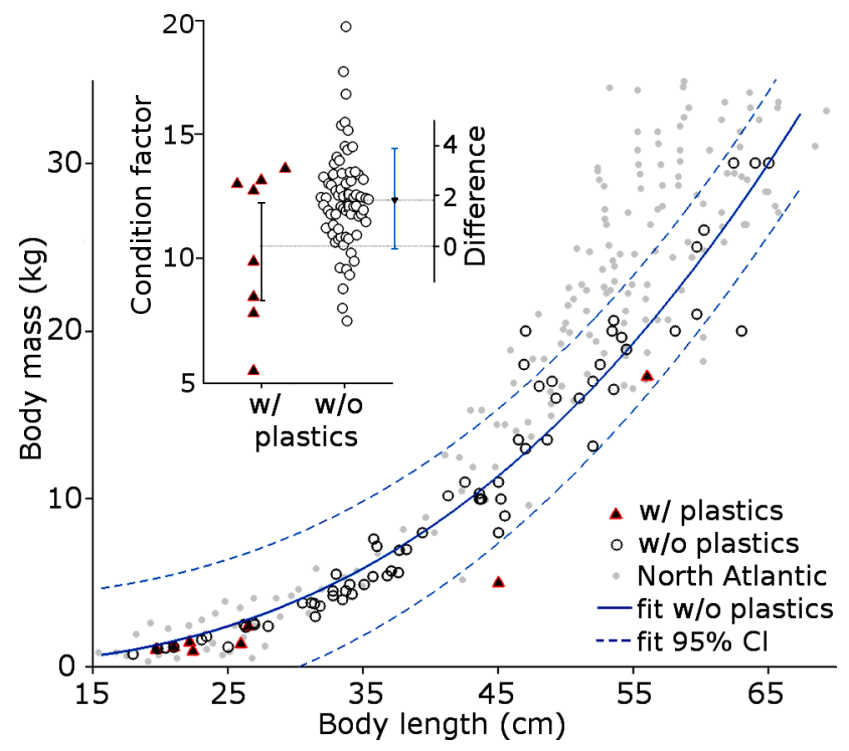

Fig. S4. Debris ingestion lowers condition. The model predicts that similarly sized loggerhead turtles who have been exposed to plastics should have lower mass, and thus lower condition than unexposed turtles. Using data on 77 loggerhead turtles obtained from the Pula aquarium in Croatia, we found preliminary evidence favoring this model prediction. Specifically, the average condition factor of eight exposed turtles is significantly lower than the average condition factor of the remaining 69 turtles (one-sided t-test, test statistic 2.35 , $\mathrm{p}$-value $p=0.011)$. The empirical difference in condition factors $(\approx 2)$ is in line with the model-predicted difference. The inset shows the estimated condition factors, including the average values and the confidence intervals obtained with the dabest package (Ho et al., 2019). Also shown is the original data in a body-mass vs. body-size plot, where the red triangles depict eight exposed individuals, while the white circles depict 69 other individuals. These turtles have been found in the Adriatic Sea and thus belong to the Mediterranean population. For comparison, gray dots depict similarly sized North Atlantic turtles (Wabnitz and Pauly, 2008).

of 120 to 150 eggs per clutch (Tiwari and Bjorndal, 2000; Hawkes et al., 2005).

Due to the stochasticity of plastics loads, the results vary between simulation runs. Here, we illustrate one typical realization. The decrease in body size of turtles exposed to plastics, who experience effective food abundance $f_{\text {eff }}$, compared to unexposed turtles, who experience food abundance $f=0.81$, is small (Fig. S5C). The small decrease in body size is explained by the average effective food abundance of $f_{\text {eff }}=0.79$ being close to $f=0.81$. Favorable feeding periods allow sea turtles to grow relatively large. In contrast, intermittent periods of high plastics loads worsen the condition of exposed turtles throughout their lifetime (Fig. S5D). With less energy available to accumulate reserve, the reproductive output declines (Fig. S5E). These results are worrying because body size in terms of carapace length is the easiest to measure in practice, and thus much more often reported than body mass and fecundity, although a combination of at least two of these quantities would be better indicators of the true state in the field. 


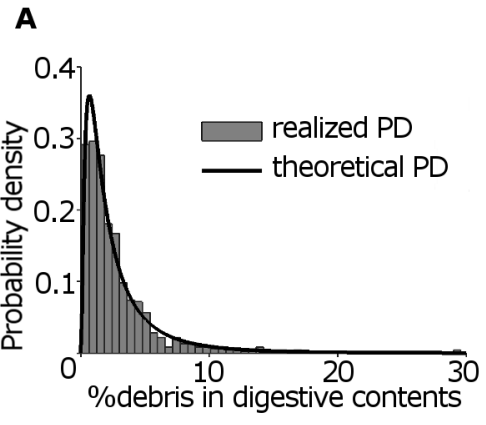

C

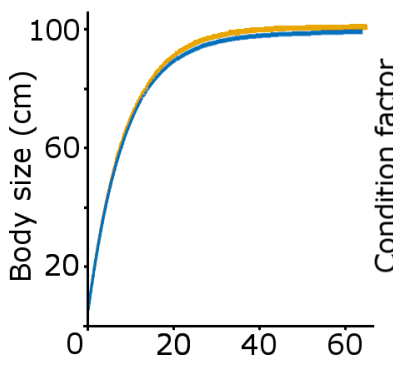

D

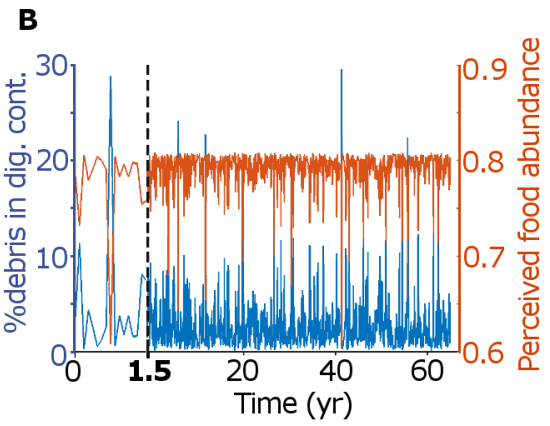

E
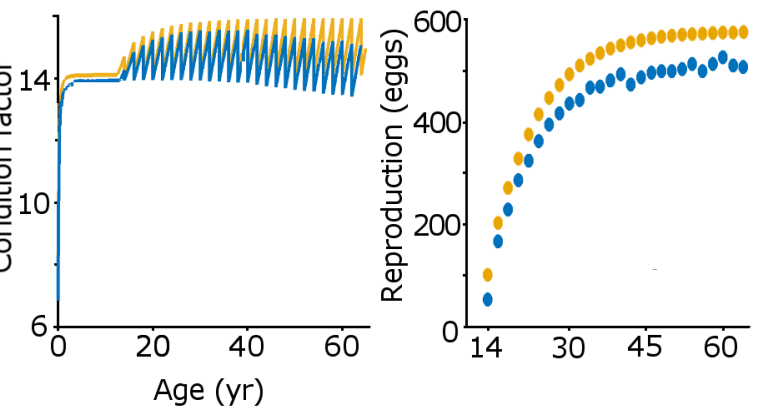

Fig. S5. Physiological response of loggerhead turtles to time-varying plastic exposure. A, We assumed that plastic load was log-normally distributed (PD - probability distribution) with parameters $\mu=0.6$ and $\sigma=1.0$. This produced the mean of $\% V_{\mathrm{dc}} \approx 3 \%$, with most values being relatively small, but occasional large spikes remained possible. B, As a consequence of the assumed probability distribution for $\% V_{\mathrm{dc}}$, the average effective food abundance in the shown simulation was $f_{\text {eff }}=0.79$. This compares to $f=0.81$ for turtles unexposed to plastics. C, Because the average effective food abundance for exposed turtles was close to that for unexposed turtles, the ultimate body size of $99.3 \mathrm{~cm}$ straight carapace length in the scenario with time-varying exposure is close to $100.8 \mathrm{~cm}$ straight carapace length in the no-exposure scenario. D, As in the main text, plastic ingestion affects body mass and the corresponding condition factor more strongly than body size. The displayed difference in condition factor arises because turtles exposed to plastics accumulate less reserve. Oscillations in the adult stage are due to reserve accumulation for reproduction. During a nesting season this energy is converted into eggs. Nesting seasons occur biannually Hawkes et al. (2005). E, Reproductive output of exposed turtles is also notably lower than that of unexposed turtles. The difference varies between any two nesting seasons depending on the realized plastic load. 


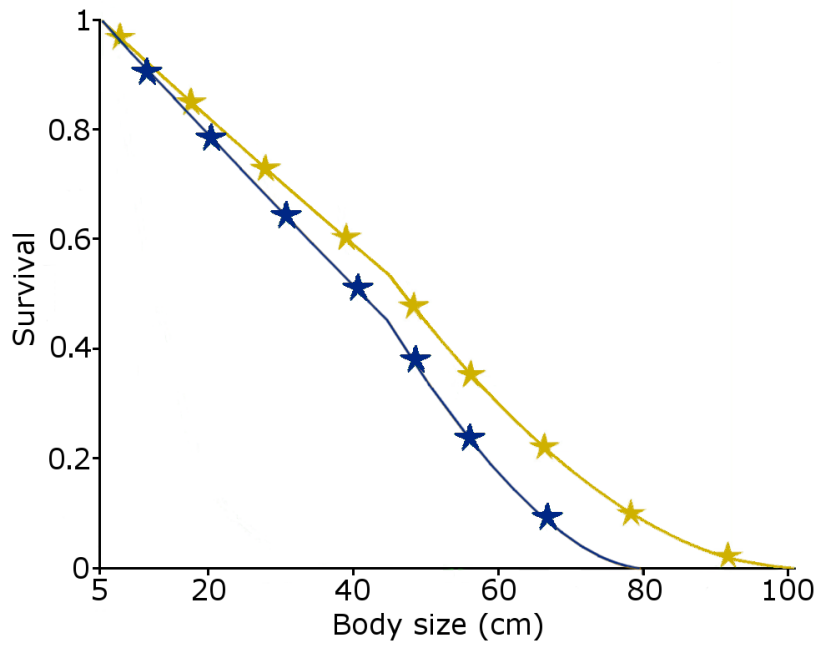

Fig. S6. Survival curves for North Atlantic loggerhead turtles. The curves show the probability of survival from size at hatching to size indicated on the x-axis. We obtained the curves by integrating size-dependent hazard rates found in the literature (Heppell et al., 2003; Sasso et al., 2006). The yellow curve is for unexposed turtles at food abundance $f=0.81$, whereas the blue curve is for turtles exposed to plastics at effective food abundance $f=0.64$. We focus on North Atlantic loggerhead turtles, but survival estimates for Mediterranean loggerheads are also available (Casale and Heppell, 2016). 
References

Barnes, D. K. A., Galgani, F., Thompson, R. C., and Barlaz, M. (2009). Accumulation and fragmentation of plastic debris in global environments. Phil. Trans. R. Soc. B, 364(1526):1985-1998.

Campani, T., Baini, M., Giannetti, M., Cancelli, F., Mancusi, C., Serena, F., Marsili, L., Casini, S., and Fossi, M. C. (2013). Presence of plastic debris in loggerhead turtle stranded along the Tuscany coasts of the Pelagos Sanctuary for Mediterranean Marine Mammals (Italy). Mar. Pollut. Bull., 74(1):225-230.

Casale, P. and Heppell, S. (2016). How much sea turtle bycatch is too much? a stationary age distribution model for simulating population abundance and potential biological removal in the mediterranean. Endanger. Species Res., $29: 239-254$.

Clukey, K. E., Lepczyk, C. A., Balazs, G. H., Work, T. M., and Lynch, J. M. (2017). Investigation of plastic debris ingestion by four species of sea turtles collected as bycatch in pelagic Pacific longline fisheries. Mar. Pollut. Bull., 120(1):117-125.

Figueiredo, G. M. and Vianna, T. M. P. (2018). Suspended microplastics in a highly polluted bay: Abundance, size, and availability for mesozooplankton. Mar. Pollut. Bull., 135:256-265.

Frick, M. G., Williams, K. L., Bolten, A. B., Bjorndal, K. A., and Martins, H. R. (2009). Foraging ecology of oceanic-stage loggerhead turtles caretta caretta. Endanger. Species Res., 9:91-97.

Hawkes, L., Broderick, A., Godfrey, M., and Godley, B. (2005). Status of nesting loggerhead turtles Caretta caretta at Bald Head island (North Carolina, USA) after 24 years of intensive monitoring and conservation. Oryx, 39:65-72.

Hays, G. C. and Speakman, J. R. (1991). Reproductive investment and optimum clutch size of loggerhead sea turtles (Caretta caretta). J. Anim. Ecol., 60(2):455-462.

Heppell, S., Crowder, L., Crouse, D., S.P., E., and Frazer, N. (2003). Population models for atlantic loggerheads: Past, present, and future. In Bolten, A. and Witherington, B., editors, Loggerhead Sea Turtles, pages 255-273. Smithsonian Institution Press, Washington D.C.

Ho, J., Tumkaya, T., Aryal, S., Choi, H., and Claridge-Chang, A. (2019). Moving beyond P values: Everyday data analysis with estimation plots. Nat. Methods, 16:565-566.

Holling, C. S. (1959). Some characteristics of simple types of predation and parasitism. Can. Entomol., 91(7):385-398.

Jusup, M., Sousa, T., Domingos, T., Labinac, V., Marn, N., Wang, Z., and Klanjšček, T. (2017). Physics of metabolic organization. Phys. Life Rev., 20:1-39.

Kooijman, S. (1998). The synthesizing unit as model for the stoichiometric fusion and branching of metabolic fluxes. Biophys. Chem., 73(1):179-188.

Kooijman, S. (2006). Pseudo-faeces production in bivalves. J. Sea Res., 56:103-106.

Kooijman, S. (2010). Dynamic Energy Budget theory for metabolic organisation. Cambridge University Press, Great Britain.

Lutz, P. (1990). Studies on the ingestion of plastic and latex by sea turtles. In Shomura, R. and Godfrey, M., editors, Proceedings of the Second International Conference on Marine Debris, pages 719-735, Honolulu. US Dept. Commerce, NOAA Tech. Memo. NMFS, NOAA-TM-NMFS-SWFS-154.

Lynch, J. M. (2018). Quantities of marine debris ingested by sea turtles: global meta-analysis highlights need for standardized data reporting methods and reveals relative risk. Environ. Sci. Technol., 52(21):12026-12038.

Marn, N., Jusup, M., Catteau, S., Kooijman, S., and Klanjšček, T. (2019). Comparative physiological energetics of Mediterranean and North Atlantic loggerhead turtles. J. Sea Res., 143:100-118.

Marn, N., Jusup, M., Legović, T., Kooijman, S., and Klanjšček, T. (2017a). Environmental effects on growth, reproduction, and life-history traits of loggerhead turtles. Ecol. Model., 360:163-178.

Marn, N., Kooijman, S., Jusup, M., Legović, T., and Klanjšček, T. (2017b). Inferring physiological energetics of loggerhead turtle (Caretta caretta) from existing data using a general metabolic theory. Mar. Environ. Res., $126: 14-25$.

Marques, G., Augustine, S., Lika, K., Pecquerie, L., Domingos, T., and Kooijman, S. (2018). The AmP project: Comparing species on the basis of dynamic energy budget parameters. PLOS Comput. Biol., 14(5):e1006100.

Mascarenhas, R., Santos, R., and Zeppelini, D. (2004). Plastic debris ingestion by sea turtle in Paraíba, Brazil. Mar. Pollut. Bull., 49(4):354-355.

Moore, C., Moore, S., Leecaster, M., and Weisberg, S. (2001). A comparison of plastic and plankton in the North Pacific central gyre. Mar. Pollut. Bull., 42(12):1297-1300.

Nash, R. D., Valencia, A. H., and Geffen, A. J. (2006). The origin of Fulton's condition factor-setting the record straight. Fisheries, 31(5):236-238.

Sasso, C. R., Braun-McNeill, J., Avens, L., and Epperly, S. P. (2006). Effects of transients on estimating survival and population growth in juvenile loggerhead turtles. Mar. Ecol. Prog. Ser., 324:287-292.

Schuyler, Q., Hardesty, B. D., Wilcox, C., and Townsend, K. (2014). Global analysis of anthropogenic debris ingestion 
by sea turtles. Conserv. Biol., 28:129-139.

Sousa, T., Domingos, T., and Kooijman, S. (2008). From empirical patterns to theory: A formal metabolic theory of life. Phil. Trans. R. Soc. B, 363(1502):2453-2464.

Sousa, T., Domingos, T., Poggiale, J.-C., and Kooijman, S. (2010). Dynamic Energy Budget theory restores coherence in biology. Phil. Trans. R. Soc. B, 365(1557):3413-3428.

Stubbs, J. L., Mitchell, N. J., Marn, N., Vanderklift, M. A., Pillans, R. D., and Augustine, S. (2019). A full life cycle Dynamic Energy Budget (DEB) model for the green sea turtle (Chelonia mydas) fitted to data on embryonic development. J. Sea Res., 143:78-88.

Tiwari, M. and Bjorndal, K. A. (2000). Variation in morphology and reproduction in loggerheads, Caretta caretta, nesting in the United States, Brazil, and Greece. Herpetologica, 56(3):343-356.

Tomás, J., Guitart, R., Mateo, R., and Raga, J. (2002). Marine debris ingestion in loggerhead sea turtles, Caretta caretta, from the Western Mediterranean. Mar. Pollut. Bull., 44:211-216.

Tucker, A. D. (2010). Nest site fidelity and clutch frequency of loggerhead turtles are better elucidated by satellite telemetry than by nocturnal tagging efforts: Implications for stock estimation. J. Exp. Mar. Biol. Ecol., 383(1):48-55.

Valente, A., Marco, I., Parga, M., Lavin, S., Alegre, F., and Cuenca, R. (2008). Ingesta passage and gastric emptying times in loggerhead sea turtles (Caretta caretta). Res. Vet. Sci., 84(1):132-139.

Wabnitz, C. and Pauly, D. (2008). Length-weight relationships and additional growth parameters for sea turtles. Fish. Cent. Res. Rep., 16(10):92-101. 